\title{
BMJ
}

\section{Prevention of pain on injection of propofol: systematic review and meta-analysis}

\author{
Leena Jalota, visiting research fellow, ${ }^{1}$ Vicki Kalira, medical student, ${ }^{1,2}$ Elizabeth George, staff research \\ associate, ${ }^{1}$ Yung-Ying Shi, staff research associate, ${ }^{1}$ Cyrill Hornuss, research fellow, ${ }^{1}$ Oliver Radke, attending \\ physician,,$^{1,3}$ Nathan L Pace, professor, ${ }^{1,4}$ Christian C Apfel, associate professor ${ }^{1}$ On behalf of the Perioperative \\ Clinical Research Core
}

\section{ABSTRACT}

Objective To systematically determine the most efficacious approach for preventing pain on injection of propofol.

Design Systematic review and meta-analysis.

Data sources PubMed, Embase, Cochrane Library, www.clinicaltrials.gov, and hand searching from the reference lists of identified papers.

Study selection Randomised controlled trials comparing drug and non-drug interventions with placebo or another intervention to alleviate pain on injection of propofol in adults.

Results Data were analysed from 177 randomised controlled trials totalling 25260 adults. The overall risk of pain from propofol injection alone was about $60 \%$. Using an antecubital vein instead of a hand vein was the most effective single intervention (relative risk $0.14,95 \%$ confidence interval 0.07 to 0.30 ). Pretreatment using lidocaine (lignocaine) in conjunction with venous occlusion was similarly effective $(0.29,0.22$ to 0.38$)$. Other effective interventions were a lidocaine-propofol admixture $(0.40,0.33$ to 0.48$)$; pretreatment with lidocaine $(0.47,0.40$ to 0.56$)$, opioids $(0.49,0.41$ to $0.59)$, ketamine $(0.52,0.46$ to 0.57$)$, or non-steroidal anti-inflammatory drugs $(0.67,0.49$ to 0.91$)$; and propofol emulsions containing medium and long chain triglycerides $(0.75,0.67$ to 0.84$)$. Statistical testing of indirect comparisons showed that use of the antecubital vein and pretreatment using lidocaine along with venous occlusion to be more efficacious than the other interventions.

Conclusions The two most efficacious interventions to reduce pain on injection of propofol were use of the antecubital vein, or pretreatment using lidocaine in conjunction with venous occlusion when the hand vein was chosen. Under the assumption of independent efficacy a third practical alternative could be pretreatment of the hand vein with lidocaine or ketamine and use of a propofol emulsion containing medium and long chain triglycerides. Although not the most effective intervention on its own, a small dose of opioids before induction halved the risk of pain from the injection and thus can generally be recommended unless contraindicated.

\section{INTRODUCTION}

Propofol is the drug of choice for induction of anaesthesia in millions of patients every year because of its rapid onset and short duration of action, easy titration, and favourable profile for side effects. ${ }^{1}$ Despite these positive attributes, about three out of five patients experience pain on injection of propofol, with one of these patients reporting severe or excruciating pain. Some patients recall the induction of anaesthesia as the most painful part of the perioperative period. As a result several interventions have been investigated to alleviate the pain associated with propofol injection. A systematic review in 2000 suggested pretreatment using lidocaine (lignocaine) in conjunction with venous occlusion as the most effective intervention. ${ }^{2}$ Despite that recommendation the technique failed to gain widespread popularity, possibly because of the time needed to apply the tourniquet. As a result the pain associated with injection of propofol remains a challenge and more than 100 new studies have explored additional and alternative strategies. These include novel propofol emulsions, ${ }^{34}$ modified emulsions, and microemulsion formulations, ${ }^{5-7}$ as well as diverse drugs and their combinations. We summarised all the available evidence from trials that compared the use of any drug or non-drug interventions (or combinations) with an active or inactive control in adults receiving intravenous propofol.

\section{METHODS}

The study was carried out according to the methods recommended by the Cochrane Collaboration and written in accordance with the PRISMA statement for reporting systematic reviews. ${ }^{89}$

This qualitative systematic review included studies published up to December 2010. We searched PubMed, Cochrane Library, and Embase using the search terms "propofol" AND ("injection pain" OR "pain on injection"). We limited our search to clinical trials and randomised controlled trials (see web extra 1 for details of search strategy).

To identify all available evidence we identified additional relevant randomised controlled trials by hand 
Table 1|Summary of most effective interventions for reducing pain from propofol injection

\begin{tabular}{|c|c|c|c|c|}
\hline Interventions & No of patients & No of studies & Control intervention* & Relative risk $+(95 \% \mathrm{Cl})$ \\
\hline Propofol injection in antecubital vein & 411 & 6 & Hand vein & $0.14(0.07$ to 0.30$)$ \\
\hline $\begin{array}{l}\text { Lidocaine pretreatment with venous } \\
\text { occlusion }\end{array}$ & 1072 & 14 & No venous occlusion & $0.29(0.22$ to 0.38$)$ \\
\hline Lidocaine-propofol admixture & 3210 & 25 & No pretreatment & $0.40(0.33$ to 0.48$)$ \\
\hline Lidocaine pretreatment & 2053 & 24 & No pretreatment & $0.47(0.40$ to 0.56$)$ \\
\hline Opioid pretreatment & 1522 & 17 & No pretreatment & $0.49(0.41$ to 0.59$)$ \\
\hline Ketamine pretreatment & 910 & 7 & No pretreatment & $0.52(0.46$ to 0.57$)$ \\
\hline NSAID pretreatment & 628 & 7 & No pretreatment & $0.67(0.49$ to 0.91$)$ \\
\hline $\begin{array}{l}\text { Propofol emulsion, medium } \\
\text { and long chain triglycerides }\end{array}$ & 2344 & 24 & $\begin{array}{l}\text { Propofol emulsion, } \\
\text { long chain triglycerides }\end{array}$ & $0.75(0.67$ to 0.84$)$ \\
\hline
\end{tabular}

NSAID=non-steroidal anti-inflammatory drug.

${ }^{\star}$ Control groups all received propofol emulsion containing long chain triglycerides. Propofol was injected in hand vein in all treatment and control groups except group assigned to antecubital vein.

†Mantel Haenszel random effects model.

searching the reference lists of the original papers until no further relevant references could be found. We also searched reviews on pain associated with propofol injection for similar randomised controlled trials. Although we applied no language restrictions, the only relevant studies were in English, German, and Japanese.

To minimise data duplication as a result of multiple reporting we compared papers from the same author. In addition, we searched www.clinicaltrials.gov for studies. Two authors (LJ and VK) screened and retrieved reports and excluded irrelevant studies. Relevant data were extracted by one author $(\mathrm{VK})$ and checked by

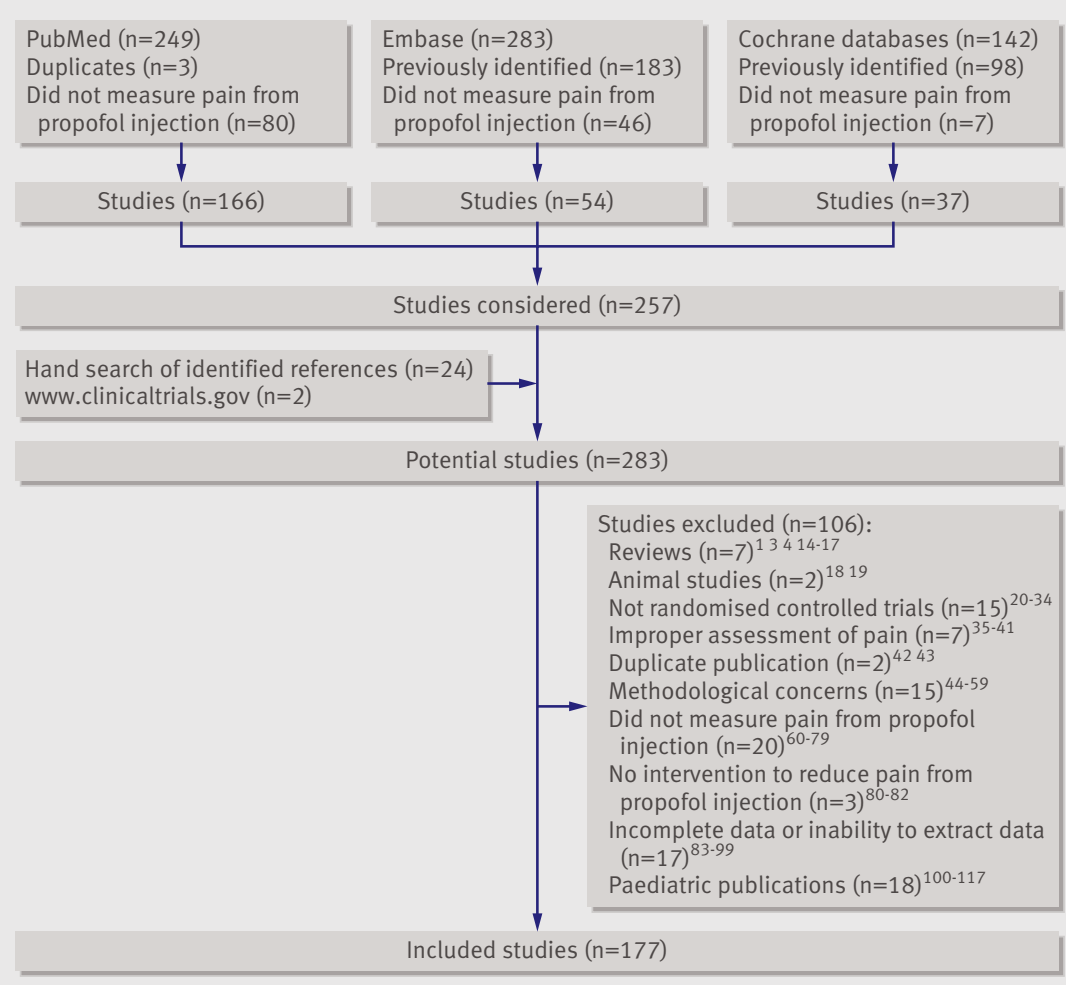

Fig 1| Flow of papers through study another (LJ). Additional investigators (CCA, OR, and NLP) participated in the review process when uncertainty about eligibility criteria arose. From each study we extracted details on patients' characteristics (adults only), use of non-drug interventions (for example, site of venous cannulation, speed of injected propofol, temperature of injected propofol), use of analgesic interventions, and use of combinations of interventions (see web extra 2 for characteristics of included studies).

\section{Selection of studies for review}

Selected studies included all randomised controlled trials that compared the use of any drug or non-drug intervention, or a combination, with an active or inactive control, and reported the response rate and severity of pain in adults receiving intravenous propofol. All included studies had numerical data presented in the text or a table; if data were not presented as such, we extracted the information from the graphs if the scale allowed a sufficiently precise estimation. We included all studies that met the eligibility criteria, regardless of language of publication.

\section{Assessment of risk of bias}

We assessed risk of bias in each of four domains in studies meeting the inclusion criteria: adequate sequence generation, adequate concealment of allocation, adequate blinding, and completeness of reporting data on outcomes (see web extra 2). The specific domains of risk of bias were graded as "yes" for low risk, "unclear," and "no" for high risk. As more than $95 \%$ of the primary studies were designed to search for pain reduction during anaesthesia induction with propofol, selective outcome reporting bias was considered unlikely and not assessed.

\section{Statistical analysis}

Meta-analyses were carried out by direct comparisons of intervention versus control (pairwise) and indirect comparisons between the network of interventions shown to be significant individually. The primary outcome was the number of patients reporting any pain 


\section{Experimental Control \\ $\overline{\text { Events Total }} \overline{\text { Events Total }}$}

Antecubital vein $\boldsymbol{v}$ hand vein (control)

$\begin{array}{lcccc}\text { Briggs 1985 } & 0 & 40 & 10 & 40 \\ \text { Scott 1988 } & 0 & 15 & 7 & 15 \\ \text { McCulloch 1985 } & 1 & 40 & 15 & 40 \\ \text { Lees 1985 } & 1 & 40 & 15 & 40 \\ \text { Briggs 1982 } & 3 & 21 & 6 & 20 \\ \text { Tariq 2006 } & 4 & 50 & 29 & 50 \\ \text { Total (95\% Cl) } & & 206 & & 20 \\ \text { Total events } & 9 & & 82 & \end{array}$

Total events $\quad 9 \quad 82$

$\mathrm{df}=5, \mathrm{P}=0.30, \mathrm{I}^{2}=18 \%$

Test for overall effect: $z=5.14, P<0.001$

Fig 2 2 Risk of pain on injection of propofol in antecubital vein or hand vein

(pain response rate); the effect size was the relative risk. We did not carry out meta-analyses of pain scores (for example, numerical or verbal rating scales) because they were reported both rarely and inconsistently. For studies with multiple intervention groups, we partitioned the count of events and patients in the control group into two or more control groups within any meta-analysis to avoid a unit of analysis error. Similarly, for the studies participating in the indirect comparisons, we partitioned the comparator group according to how many times it was used for indirect comparisons (across meta-analyses). The summary relative risks and 95\% confidence intervals were estimated using a random effects Mantel-Haenszel method in RevMan 5.0 (Cochrane Collaboration). Statistical heterogeneity was assessed by the $\mathrm{I}^{2}$ value. If interventions involved 10 or more studies, we used funnel plots to visualise small study effects or reporting bias; asymmetry was tested using the arcsine transformation and method of moments linear regression implemented in the $\mathrm{R}$ package meta ( $\mathrm{R}$ Foundation for Statistical Computing, Austria). ${ }^{10}$ We considered $\mathrm{P}$ values less than 0.05 and relative risks not crossing the identity line as statistically significant.

We analysed the network of randomised controlled trials within an indirect comparison framework using previously described models ${ }^{11}$ and implemented in frequentist mixed effects metaregression ${ }^{12}$; we selected only interventions that significantly reduced pain by a direct intervention comparison with six or more included studies. The summary statistic was the relative risk, with 95\% confidence intervals. The common comparator was the placebo or control group. The moderators in the mixed effects models were the interventions entered as categorical covariates. Assumptions in this analysis included a sufficient homogeneity of the different trials, treatment effects ( $\log R R)$ distributed normally around a typical value, and the same residual heterogeneity $\left(\tau^{2}\right)$ among the moderators. This analysis was carried out using the $\mathrm{R}$ package metafor using restricted maximum likelihood estimation (see web extra 3 for details of the model). We adjusted the test statistics of individual estimates of moderator variables and omnibus hypotheses of all moderators by the method of Knapp and Hartung ( $\mathrm{t}$ and $\mathrm{F}$ distributions). ${ }^{13}$ Residual heterogeneity was assessed by $\chi^{2}$ tests. As the methods of estimation are different, the relative risk values from RevMan and metafor differ slightly.

\section{RESULTS}

A search of PubMed, Embase, and Cochrane databases identified 674 potentially relevant papers (fig 1), of which 427 were excluded: 83 of the 249

\begin{tabular}{|c|c|c|c|c|c|c|}
\hline Intervention & Control & $\begin{array}{c}\text { No of } \\
\text { studies }\end{array}$ & $\begin{array}{c}\text { No of } \\
\text { patients }\end{array}$ & $\begin{array}{l}\text { Relative risk* } \\
\quad(95 \% \mathrm{Cl})\end{array}$ & $\begin{array}{l}\text { Heterogeneity } \\
\mathrm{I}^{2}(\%), \mathrm{P} \text { value }\end{array}$ & References \\
\hline Bacteriostatic saline & None & 1 & 78 & $0.45(0.30$ to 0.69$)$ & NA & 138 \\
\hline Speed of intravenous carrier fluid & No intravenous carrier fluid & 4 & 299 & $1.16(0.98$ to 1.36$)$ & $0,0.50$ & $119 ; 122 ; 245 ; 246$ \\
\hline Microfiltration & No filter & 2 & 455 & $0.82(0.51$ to 1.34$)$ & $92,<0.001$ & $127 ; 128$ \\
\hline Mechanical interventions & No intervention & 4 & 291 & $0.69(0.38$ to 1.25$)$ & $0.86,<0.001$ & $30 ; 121 ; 122 ; 174 ; 247$ \\
\hline \multicolumn{7}{|l|}{ Rate of propofol infusion: } \\
\hline Overall & - & 3 & 181 & 0.84 (0.48 to 1.49$)$ & $75,0.02$ & \\
\hline Fast infusion & About $2.5 \mathrm{~mL} / \mathrm{sec}$ & 1 & 30 & 1.57 (0.84 to 2.92$)$ & NA & 119 \\
\hline $2 \mathrm{~mL} / \mathrm{sec}$ & $1 \mathrm{~mL} / \mathrm{sec}$ & 1 & 100 & $0.48(0.27$ to 0.85$)$ & NA & 120 \\
\hline $1 \mathrm{~mL} / \mathrm{sec}$ & $13.3 \mathrm{~mL} / \mathrm{sec}$ & 1 & 51 & $0.83(0.62$ to 1.12$)$ & NA & 248 \\
\hline \multicolumn{7}{|l|}{ Temperature of infused propofol: } \\
\hline $4^{\circ} \mathrm{C}$ & Room temperature & 9 & 583 & 0.82 (0.64 to 1.04$)$ & $81,<0.001$ & $90 ; 129 ; 130 ; 132-137$ \\
\hline $37^{\circ} \mathrm{C}$ & Room temperature & 4 & 301 & 0.91 (0.65 to 1.27$)$ & $83,<0.001$ & $131 ; 135-137$ \\
\hline \multicolumn{7}{|l|}{ Site of injection: } \\
\hline Overall & - & 7 & 437 & 0.14 (0.07 to 0.27$)$ & $6,0.38$ & \\
\hline Antecubital fossa vein & Hand vein & 6 & 411 & $0.14(0.07$ to 0.30$)$ & $18,0.30$ & $119 ; 123-126 ; 139$ \\
\hline Central vein & Peripheral vein & 1 & 26 & 0.07 (0.00 to 1.06$)$ & NA & 122 \\
\hline Venous occlusion & No venous occlusion & 1 & 22 & 0.82 (0.35 to 1.89$)$ & NA & 119 \\
\hline
\end{tabular}

$\mathrm{NA}=$ not applicable.

*Mantel Haenszel random effects model. 
Table 3|Efficacy results of drug interventions to reduce pain from propofol injection

\begin{tabular}{|c|c|c|c|c|c|c|}
\hline Intervention & Control & $\begin{array}{l}\text { No of } \\
\text { studies }\end{array}$ & $\begin{array}{c}\text { No of } \\
\text { patients }\end{array}$ & $\begin{array}{l}\text { Relative risk* } \\
\qquad(95 \% \mathrm{Cl})\end{array}$ & $\begin{array}{l}\text { Heterogeneity } I^{2}(\%), \\
\text { P value }\end{array}$ & References \\
\hline$\alpha_{2}$ agonist pretreatment & No pretreatment & 2 & 181 & $0.81(0.68$ to 0.97$)$ & $56,0.13$ & $249 ; 250$ \\
\hline Antiemetic pretreatment & No pretreatment & 5 & 430 & $0.47(0.32$ to 0.69$)$ & $61,0.04$ & $161 ; 162 ; 167 ; 235 ; 251$ \\
\hline \multicolumn{7}{|l|}{ Barbiturates: } \\
\hline Pretreatment & No pretreatment & 1 & 108 & $0.30(0.14$ to 0.62$)$ & $38,0.18$ & 166 \\
\hline Admixture & No admixture & 4 & 363 & 0.50 (0.28 to 0.89$)$ & $85,<0.001$ & $133 ; 252-254$ \\
\hline Benzodiazepine pretreatment & No pretreatment & 4 & 270 & $0.78(0.34$ to 1.77$)$ & $81,0.001$ & $255-258$ \\
\hline Cholinesterase inhibitor pretreatment & No pretreatment & 1 & 70 & $0.53(0.36$ to 0.78$)$ & NA & 259 \\
\hline Dextrose $5 \%$ in Ringer's lactate solution-propofol admixture & No admixture & 1 & 56 & $0.48(0.27$ to 0.85$)$ & NA & 156 \\
\hline Kallikrein inhibitor pretreatment & No pretreatment & 2 & 413 & $0.61(0.52$ to 0.72$)$ & $0,0.78$ & $135 ; 260$ \\
\hline \multicolumn{7}{|l|}{ Lidocaine: } \\
\hline Admixture & No admixture & 25 & 3210 & $0.40(0.33$ to 0.48$)$ & $79,<0.001$ & \\
\hline 5-10 mg lidocaine & No admixture & 9 & 963 & $0.44(0.32$ to 0.60$)$ & $78,<0.001$ & $125 ; 126 ; 140 ; 141 ; 143 ; 144 ; 148 ; 150 ; 158$ \\
\hline 20-30 mg lidocaine & No admixture & 7 & 490 & $0.37(0.24$ to 0.56$)$ & $76,<0.001$ & $138 ; 140 ; 142 ; 144 ; 146 ; 148 ; 158$ \\
\hline$>40$ mg lidocaine & No admixture & 18 & 1757 & $0.38(0.29$ to 0.50$)$ & $81,<0.001$ & $\begin{array}{c}135 ; 140 ; 141 ; 144-147 ; 149 ; 151-153 ; \\
156-160 ; 181 ; 261\end{array}$ \\
\hline Admixture & Lidocaine+propofol & & & & & \\
\hline Barbiturate-propofol admixture & Lidocaine+propofol & 2 & 196 & $0.54(0.26$ to 1.11$)$ & $52,0.12$ & $262 ; 263$ \\
\hline Pretreatment & No pretreatment & 24 & 2053 & 0.47 (0.40 to 0.56$)$ & $61,<0.001$ & \\
\hline 5-20 mg lidocaine & No pretreatment & 13 & 1104 & $0.54(0.45$ to 0.65$)$ & $36,0.07$ & $\begin{array}{c}119 ; 125 ; 146 ; 150 ; 165 ; 167 ; 170 ; 171 ; \\
173-176 ; 200\end{array}$ \\
\hline 30-40 mg lidocaine & No pretreatment & 7 & 464 & $0.38(0.25$ to 0.58$)$ & $68,<0.01$ & $159 ; 165 ; 166 ; 168 ; 169 ; 171 ; 177$ \\
\hline$>50 \mathrm{mg}$ lidocaine & No pretreatment & 6 & 485 & $0.40(0.22$ to 0.70$)$ & $81,<0.001$ & $70 ; 150 ; 161-164$ \\
\hline Pretreatment: & Admixture & 12 & 1547 & & & \\
\hline Ketamine pretreatment & Lidocaine+propofol & 1 & 89 & $0.10(0.04$ to 0.23$)$ & NA & 264 \\
\hline Antiemetic pretreatment & Lidocaine+propofol & 1 & 100 & $0.44(0.19$ to 1.00$)$ & NA & 265 \\
\hline Kallikrein inhibitor pretreatment & Lidocaine+propofol & 1 & 303 & 0.97 (0.61 to 1.53$)$ & NA & 266 \\
\hline Stimulant pretreatment & Lidocaine+propofol & 1 & 156 & $0.54(0.40$ to 0.74$)$ & $0,0.80$ & 267 \\
\hline Magnesium sulphate pretreatment & No pretreatment & 3 & 400 & $0.41(0.34$ to 0.51$)$ & $0,0.92$ & $168 ; 268 ; 269$ \\
\hline Nitroglycerine pretreatment & No pretreatment & 3 & 269 & $0.55(0.32$ to 0.97$)$ & $88,<0.001$ & $270-272$ \\
\hline \multicolumn{7}{|l|}{ Nitrous oxide pretreatment: } \\
\hline Nitrous oxide+oxygen & Oxygen pretreatment & 1 & 90 & $0.42(0.24$ to 0.75$)$ & NA & 273 \\
\hline Nitrous oxide+oxygen pretreatment & Lidocaine+propofol & 3 & 245 & $0.41(0.27$ to 0.62$)$ & $0,0.43$ & $273-275$ \\
\hline Ketamine pretreatment & No pretreatment & 7 & 910 & $0.56(0.47$ to 0.67$)$ & $66,<0.001$ & $164 ; 168 ; 192-196$ \\
\hline NSAIDs pretreatment & No pretreatment & 7 & 628 & $0.67(0.49$ to 0.91$)$ & $69,<0.001$ & $147 ; 177 ; 197-201$ \\
\hline Opioids pretreatment & No pretreatment & 17 & 1522 & 0.49 (0.41 to 0.59$)$ & $63,<0.001$ & 70;161;163;173;179-191 \\
\hline $1 \%$ propofol concentration & $2 \%$ propofol & 1 & 49 & $213(0.45$ to 10.12$)$ & NA & 276 \\
\hline Propofol pretreatment & No pretreatment & 1 & 60 & $0.20(0.07$ to 0.62$)$ & NA & 256 \\
\hline $\begin{array}{l}1 \% \text { microemulsion propofol (Aquafol; Daewon Pharmaceutical, } \\
\text { Seoul, Republic of Korea) }\end{array}$ & Long chain trigylcerides & 1 & 288 & $\begin{array}{l}10.52(6.06 \text { to } \\
18.27)\end{array}$ & NA & 86 \\
\hline \multicolumn{7}{|l|}{ Propofol emulsions: } \\
\hline Medium and long chain triglycerides & Long chain triglycerides & 24 & 2344 & $0.75(0.67$ to 0.84$)$ & $57,<0.001$ & $5 ; 6 ; 151 ; 177 ; 197 ; 202-219$ \\
\hline Propofol emulsions+lidocaine & Propofol emulsion & 12 & 2240 & $0.61(0.44$ to 0.84$)$ & $83,<0.001$ & $149 ; 151 ; 203 ; 206 ; 220-227$ \\
\hline Stimulants pretreatment & No pretreatment & 2 & 208 & $0.56(0.34$ to 0.93$)$ & $84,<0.001$ & $277 ; 278$ \\
\hline Steroids pretreatment & No pretreatment & 1 & 70 & 0.41 (0.24 to 0.69$)$ & NA & 279 \\
\hline Topical anaesthetics & Placebo ointment & 4 & 369 & $0.66(0.42$ to 1.01$)$ & $76,<0.01$ & $153 ; 160 ; 176 ; 280$ \\
\hline Vasodilator pretreatment & No pretreatment & 1 & 120 & $0.39(0.26$ to 0.59$)$ & NA & 281 \\
\hline Multiple drugs or interventions: & & 7 & 533 & & & \\
\hline Opioid+benzodiazepine pretreatment & $\begin{array}{l}\text { Normal saline } \\
\text { pretreatment }\end{array}$ & 1 & 50 & $0.33(0.12$ to 0.89$)$ & NA & 190 \\
\hline Opioid+benzodiazepine+lidocaine pretreatment & Opioid pretreatment & 1 & 46 & 0.07 (0.01 to 0.49$)$ & NA & 282 \\
\hline Opioid+benzodiazepine pretreatment & Opioid pretreatment & 1 & 48 & $0.31(0.11$ to 0.84$)$ & NA & 282 \\
\hline Opioid-lidocaine admixture & Opioid pretreatment & 1 & 48 & $0.62(0.28$ to 1.36$)$ & NA & 282 \\
\hline Opioid pretreatment and lidocaine-propofol admixture & Opioid pretreatment & 1 & 102 & $0.27(0.11$ to 0.66$)$ & NA & 262 \\
\hline Nitrous oxide pretreatment+lidocaine pretreatment & $\begin{array}{l}\text { Nitrous oxide } \\
\text { pretreatment }\end{array}$ & 1 & 66 & $0.36(0.15$ to 0.88$)$ & NA & 274 \\
\hline $\begin{array}{l}\text { Ketamine pretreatment followed by lidocaine-propofol } \\
\text { admixture }\end{array}$ & Saline pretreatment & 1 & 122 & $0.22(0.09$ to 0.54$)$ & NA & 264 \\
\hline $\begin{array}{l}\text { Benzodiazepine (oral)+NSAID (oral)+paracetamol } \\
\text { (acetaminophen, oral)+opioid pretreatment (intravenous) }\end{array}$ & Saline pretreatment & 1 & 209 & $0.60(0.42$ to 0.85$)$ & NA & 283 \\
\hline
\end{tabular}




\section{Experimental Control}

Events Total Events Total

Lidocaine 5 mg - 10 mg admixture

Gajraj 1996

Gajraj 1996

Gehan 1991

Gehan 1991

Helbo-Hansen 198810

Ho 1999

King 1992

King 1992

Madenoglu 2003

McCulloch 1985

Tariq 2006

Tham 1995

Subtotal $(95 \% \mathrm{Cl})$

$\begin{array}{ll}9 & 27 \\ 5 & 27 \\ 3 & 86 \\ 3 & 71\end{array}$

27
27
86

$$
\begin{gathered}
6 \\
5 \\
10
\end{gathered}
$$

6
5
10

7
6
26

$\begin{array}{lll}40 & 21 & 40\end{array}$

$\begin{array}{llll}46 & 60 & 18 & 20\end{array}$

$\begin{array}{llll}29 & 90 & 24 & 33\end{array}$

$\begin{array}{llll}46 & 91 & 24 & 33\end{array}$

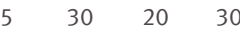

$\begin{array}{lll}40 & 15 & 40\end{array}$

$\begin{array}{lll}50 & 29 & 50\end{array}$

$\mathrm{df}=11, \mathrm{P}<0.001, \mathrm{I}^{2}=78 \%$

Test for overall effect: $z=5.06, P<0.001$

$\begin{array}{lcccc}\text { Lidocaine } 20 & \text { mg - } 30 & \text { mg } & \text { admixture } \\ \text { Gajraj 1996 } & 2 & 27 & 6 & 7 \\ \text { Goldmann 1997 } & 11 & 25 & 19 & 25 \\ \text { Ho 1999 } & 5 & 60 & 18 & 20 \\ \text { Johnson 1990 } & 1 & 18 & 6 & 11 \\ \text { King 1992 } & 28 & 89 & 24 & 32 \\ \text { Minogue 2005 } & 22 & 42 & 33 & 39 \\ \text { Tham 1995 } & 9 & 25 & 23 & 29 \\ \text { Tham 1995 } & 11 & 23 & 14 & 18 \\ \text { Subtotal (95\% Cl) } & & 309 & & 18\end{array}$

Test for heterogeneity: $\tau^{2}=0.24, \chi^{2}=29.25$,

$\mathrm{df}=7, \mathrm{P}<0.001, \mathrm{I}^{2}=76 \%$

Test for overall effect: $z=4.66, P<0.001$

\section{Lidocaine $\mathbf{2 4 0} \mathbf{~ m g}$ admixture}

\section{Gajraj 1996}

Gehan 1991

Ho 1999

Inoue 1997

Johnson 1990

Karasawa 2000

Krobbuaban 2005

Krobbuaban 2005

Mallick 2007

Massad 2006

Mccluskey 2003

Nakane 1999

Nakayama 2001

Nathanson 1996

Nonaka 1999

Nonaka 2000

Nonaka 2000

Tham 1995

Tsubokura 2001

Yokota 1997

Subtotal $(95 \% \mathrm{Cl})$

$\begin{array}{cc}2 & 27 \\ 14 & 76 \\ 6 & 60 \\ 11 & 54\end{array}$

1154

$0 \quad 22$

$10 \quad 50$

$48 \quad 96$

$\begin{array}{ll}38 & 97 \\ 22 & 82\end{array}$

$\begin{array}{ll}22 & 82 \\ 26 & 50\end{array}$

$26 \quad 50$

$\begin{array}{ll}11 & 30 \\ 61 & 100\end{array}$

220

430

$8 \quad 32$

416

630

622

220

630

$\mathrm{df}=19, \mathrm{P}<0.001, \mathrm{I}^{2}=81 \%$

Test for overall effect: $z=6.80, P<0.001$

\begin{tabular}{|c|c|c|c|c|c|c|}
\hline Total $(95 \% \mathrm{Cl})$ & 326 & & & & \multirow{2}{*}{\multicolumn{2}{|c|}{$100.00 .40(0.33$ to 0.48$)$}} \\
\hline Total events & & & & & & \\
\hline \multirow{2}{*}{$\begin{array}{l}\text { Test for heterogeneity: } \tau^{2}=0.22, \chi^{2}=183.73 \text {, } \\
d f=39, P<0.001, I^{2}=79 \% \\
\text { Test for overall effect: } z=9.95, P<0.001\end{array}$} & 0.002 & 0.1 & 1 & 10 & 500 & \\
\hline & \multicolumn{2}{|c|}{$\begin{array}{l}\text { Favours } \\
\text { intervention }\end{array}$} & & \multicolumn{2}{|c|}{$\begin{array}{r}\text { Favours } \\
\text { control }\end{array}$} & \\
\hline
\end{tabular}

Fig 3 | Risk of pain on injection of lidocaine-propofol admixture

identified through PubMed (three were duplicates and 80 did not measure pain from propofol injection), 229 of the 283 identified through Embase (183 were identified in the previous search and 46 did not measure pain from propofol injection), and 105 of the 142 identified through the Cochrane databases (98 were previously identified and seven did not measure pain from propofol injection). In addition to the 257 potential studies a further 24 were identified after hand searching references of relevant papers, and two were from the US government clinical trials website (www.clinicaltrials.gov). Thus, 283 studies were retrieved as potential clinical trials for further evaluation. A further 106 studies were excluded for the following reasons: reviews (seven studies), ${ }^{13414-17}$ not carried out in humans $(\mathrm{n}=2),{ }^{1819}$ not randomised controlled trials $(\mathrm{n}=15),{ }^{20-34}$ improper assessment of pain $(\mathrm{n}=7),{ }^{35-41}$ duplicate publication $(\mathrm{n}=2),{ }^{42}{ }^{43}$ methodological concerns $(n=15),{ }^{44-59}$ did not measure pain on injection of propofol $(\mathrm{n}=20),{ }^{60-79}$ intervention not aimed at pain reduction on injection of propofol $(\mathrm{n}=3),{ }^{80-82}$ incomplete data or inability to extract data $(\mathrm{n}=17),{ }^{83-99}$ and studies in children $(\mathrm{n}=18) .{ }^{100-117}$ Thus 177 studies were included in the analysis.

Overall, a low risk of bias was identified for adequate sequence generation in $40 \%$ of included studies $(n=71)$, adequate allocation concealment in $43 \%(n=76)$, blinding in $85 \%(\mathrm{n}=151)$, and whether incomplete outcome data were addressed in $88 \%(n=156)$.

Thus this systematic review includes data from 25260 adults (177 randomised controlled trials). The average trial size was 142 patients (range 24 to 388 ). Nineteen drugs and eight different non-drug interventions and combinations were tested (see web extra figure). About $60 \%$ of patients in the control group reported pain on injection of propofol alone. Trials reported pain scores rarely and on different scales. Therefore this analysis is based exclusively on the response rate of pain.

Because of the wide variety of interventions investigated, three categories of studies were established: non-drug interventions, drug interventions and their combinations, and both drug and non-drug interventions. Each category was further divided into several subcategories. Finally, subanalyses were carried out for interventions involving more than five studies.

\section{Efficacy according to categories \\ Non-drug category}

The non-drug category consisted of studies that used mechanical interventions such as different infusion rates, ${ }^{118-120}$ venous occlusion, ${ }^{119}$ needle sizes ${ }^{121}$ injection sites, ${ }^{122-126}$ microfiltration, ${ }^{127128}$ temperature, ${ }^{90}{ }^{129-137}$ and bacteriostatic saline. ${ }^{138}$ The most efficacious intervention in this subcategory was selection of an antecubital vein compared with a hand vein as the injection site (relative risk $0.14,95 \%$ confidence interval 0.07 to 0.30 ; table 1 and fig 2). ${ }^{119123-126139}$ Conversely, non-effective interventions were cold propofol $\left(4^{\circ} \mathrm{C}\right)$, propofol at room temperature, venous occlusion by itself, and modifying the speed of the intravenous carrier fluid (table 2).

\section{Drug category}

The drug category comprised various drugs or drug combinations (table 3 ). The studies were divided into 
Table $4 \mid$ Efficacy results of drug and non-drug interventions to reduce pain from propofol injection

\begin{tabular}{|c|c|c|c|c|c|c|}
\hline Intervention & Control & $\begin{array}{l}\text { No of } \\
\text { studies }\end{array}$ & $\begin{array}{l}\text { No of } \\
\text { patients }\end{array}$ & $\begin{array}{l}\text { Relative risk* } \\
\quad(95 \% \mathrm{Cl})\end{array}$ & $\begin{array}{l}\text { Heterogeneity } I^{2}(\%) \\
\text { P value }\end{array}$ & References \\
\hline Ionophoretically applied lidocaine & Sham & 1 & 40 & $0.31(0.14$ to 0.69$)$ & NA & 237 \\
\hline \multicolumn{7}{|l|}{ Site of injection (antecubital or dorsum): } \\
\hline Lidocaine (antecubital) & Propofol (antecubital) & 2 & 105 & $0.18(0.04$ to 0.86$)$ & $27,0.24$ & $119 ; 126$ \\
\hline Lidocaine+propofol (antecubital) & Lidocaine+propofol (dorsum) & 1 & 75 & $0.80(0.17$ to 3.84$)$ & $0,0.07$ & 126 \\
\hline $\begin{array}{l}\text { Pethidine+atropine pretreatment and propofol } \\
\text { (antecubital) }\end{array}$ & $\begin{array}{l}\text { Pethidine+atropine pretreatment } \\
\text { and propofol (dorsum) }\end{array}$ & 2 & 130 & $0.17(0.05$ to 0.55$)$ & $0,0.81$ & $123 ; 124$ \\
\hline $\begin{array}{l}\text { Diazepam (oral) pretreatment and propofol } \\
\text { (antecubital) }\end{array}$ & $\begin{array}{l}\text { Diazepam (oral) pretreatment } \\
\text { and propofol (dorsum) }\end{array}$ & 2 & 113 & 0.10 (0.01 to 0.79$)$ & $0,0.03$ & $123 ; 124$ \\
\hline Papaveretum+hyoscine pretreatment (antecubital) & $\begin{array}{l}\text { Papaveretum+hyoscine } \\
\text { pretreatment (dorsum) }\end{array}$ & 1 & 52 & $0.18(0.04$ to 0.74$)$ & NA & 124 \\
\hline \multicolumn{7}{|l|}{ Temperature of infused propofol $\left(4^{\circ} \mathrm{C} / 37^{\circ} \mathrm{C}\right)$ : } \\
\hline Propofol at room temperature+nafamostat & Propofol at room temperature & 1 & 100 & $0.55(0.40$ to 0.74$)$ & NA & 135 \\
\hline Propofol at room temperature+lidocaine $10 \mathrm{mg}$ & Propofol at room temperature & 1 & 25 & $0.56(0.29$ to 1.08$)$ & NA & 132 \\
\hline Propofol at room temperature+lidocaine $20 \mathrm{mg}$ & Propofol at room temperature & 1 & 25 & $0.31(0.13$ to 0.75$)$ & NA & 132 \\
\hline Propofol at $4^{\circ} \mathrm{C}+$ lidocaine $10 \mathrm{mg}$ & Propofol at $4^{\circ} \mathrm{C}$ & 1 & 25 & $0.50(0.25$ to 1.00$)$ & NA & 132 \\
\hline Propofol at $4^{\circ} \mathrm{C}+$ lidocaine $20 \mathrm{mg}$ & Propofol at $4^{\circ} \mathrm{C}$ & 1 & 25 & $0.06(0.01$ to 0.44$)$ & NA & 132 \\
\hline Propofol at room temperature+lidocaine $40 \mathrm{mg}$ & Propofol at $4^{\circ} \mathrm{C}+$ lidocaine $40 \mathrm{mg}$ & 1 & 30 & $0.42(0.17$ to 1.04$)$ & NA & 133 \\
\hline Propofol+lidocaine $0.1 \mathrm{mg} / \mathrm{kg}$ & Propofol at $4^{\circ} \mathrm{C}$ & 1 & 58 & 1.59 (1.16 to 2.18$)$ & NA & 90 \\
\hline Propofol+lidocaine $0.2 \mathrm{mg} / \mathrm{kg}$ & Propofol at $4^{\circ} \mathrm{C}$ & 1 & 57 & 1.80 (1.31 to 2.48$)$ & NA & 90 \\
\hline Lidocaine pretreatment followed by propofol at $4^{\circ} \mathrm{C}$ & Propofol at $4^{\circ} \mathrm{C}$ & 1 & 40 & $0.28(0.13$ to 0.60$)$ & NA & 133 \\
\hline Drugs with venous occlusion (manual or tourniquet): & Without venous occlusion & & & & & \\
\hline Antiemetics & None & 2 & 200 & 0.54 (0.40 to 0.72$)$ & $77,0.04$ & $233 ; 236$ \\
\hline Barbiturates & None & 2 & 112 & $0.20(0.11$ to 0.36$)$ & $85,0.010$ & $228 ; 284$ \\
\hline$\beta$ blockers & None & 2 & 160 & $0.49(0.37$ to 0.64$)$ & $22,0.26$ & $230 ; 285$ \\
\hline Kallikrein inhibitors & None & 1 & 101 & $0.54(0.38$ to 0.76$)$ & NA & 286 \\
\hline Lidocaine & None & 14 & 1052 & $0.29(0.22$ to 0.38$)$ & $59,<0.01$ & $\begin{array}{c}133 ; 142 ; 152 ; 177 ; \\
228-236\end{array}$ \\
\hline Ketamine & None & 3 & 200 & $0.31(0.22$ to 0.44$)$ & $96,<0.001$ & $231 ; 284 ; 287$ \\
\hline NSAIDs & None & 6 & 670 & $0.52(0.44$ to 0.60$)$ & $67,<0.001$ & $\begin{array}{c}177 ; 199 ; 201 ; 232 ; \\
288 ; 289\end{array}$ \\
\hline Opioids & None & 2 & 100 & $0.76(0.60$ to 0.97$)$ & $92,<0.001$ & $229 ; 284$ \\
\hline Steroids & None & 1 & 70 & $0.42(0.27$ to 0.66$)$ & NA & 234 \\
\hline Stimulants & None & 1 & 50 & $0.95(0.73$ to 1.24$)$ & NA & 287 \\
\hline Opioids+lidocaine & Lidocaine+venous occlusion & 1 & 64 & $0.13(0.02$ to 0.90$)$ & NA & 290 \\
\hline Opioids+lidocaine & Opioids+venous occlusion & 1 & 63 & $0.11(0.02$ to 0.78$)$ & NA & 290 \\
\hline Lidocaine+ketamine+venous occlusion & Lidocaine+venous occlusion & 1 & 64 & $0.22(0.07$ to 0.65$)$ & NA & 291 \\
\hline Lidocaine+ketamine+venous occlusion & Ketamine+venous occlusion & 1 & 66 & $0.39(0.15$ to 0.99$)$ & NA & 291 \\
\hline
\end{tabular}

$N A=$ not applicable; NSAID=non-steroidal anti-inflammatory drug.

*Mantel Haenszel random effects model.

19 subcategories based on drug class-for example, antiemetics, local anaesthetics, benzodiazepines, barbiturates. Most of these drugs were partially successful in reducing the risk of pain from propofol injection.

A lidocaine-propofol admixture (25 trials) was the most effective intervention in this subcategory $(0.40$, 0.33 to 0.48 , fig 3). ${ }^{125126135138140-160}$ The funnel plot was, however, asymmetrical (arcsine transformation regression, $\mathrm{t}=-5.3, \mathrm{df}=39, \mathrm{P}<0.001$ ) suggesting a strong small study effect or reporting bias for this intervention (fig 4). No other funnel plots were asymmetrical. A lidocaine-propofol admixture was of similar efficacy to pretreatment with lidocaine alone (24 studies) (0.47, 0.40 to 0.56 , fig 5). ${ }^{70119125146150159161-178}$

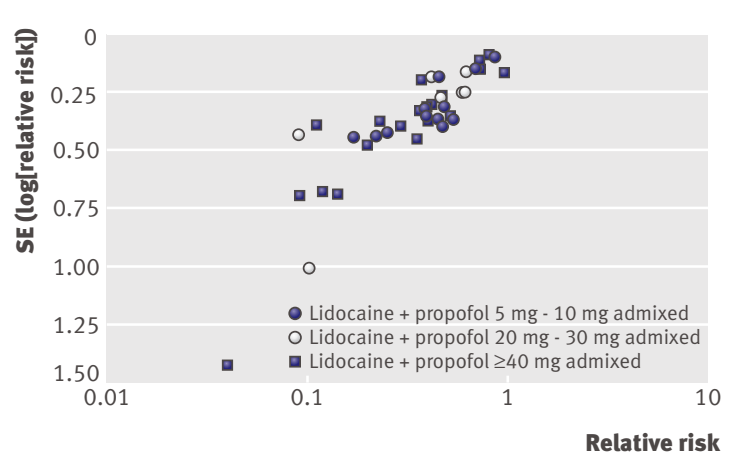

Fig 4 | Funnel plot of studies using lidocaine-propofol admixture 


\section{Experimental Control}

Events Total Events Total

Lidocaine 5 mg - 20 mg pretreatment

Adachi 2002

Adachi 2002

McDonald 1996

Johnson 1990

Scott 1988

Adachi 2002

Ganta 1992

McCulloch 1985

Smith 1996

Kaya 2008

Lee 1994

Newcombe 1990

Lyons 1996

Nicol 1991

Madenoglu 2003

Scott 1988

Scott 1988

Subtotal $(95 \% \mathrm{Cl})$

Test for heterogeneity: $\tau^{2}=0.05, \chi^{2}=25.10$

$\mathrm{df}=16, \mathrm{P}=0.07, \mathrm{I}^{2}=36 \%$

Test for overall effect: $z=6.52, P<0.001$

\section{Lidocaine $\mathbf{3 0} \mathbf{~ m g ~ - ~} 40 \mathrm{mg}$ pretreatment}

$\begin{array}{lccc}\text { Tsubokura 2001 } & 2 & 20 & 14 \\ \text { Honarmand 2008 } & 9 & 50 & 44 \\ \text { Adachi 2002 } & 4 & 22 & 4 \\ \text { Lee 2004 } & 4 & 50 & 14 \\ \text { Oka 2008 } & 9 & 20 & 18 \\ \text { Kajiyama 2009 } & 24 & 60 & 42 \\ \text { Azma 2004 } & 16 & 29 & 6 \\ \text { Subtotal }(95 \% \mathrm{Cl}) & & 251 & \end{array}$

Subtotal $(95 \% \mathrm{Cl})$

251

Test for heterogeneity: $\tau^{2}=0.19, \chi^{2}=18.62$, $\mathrm{df}=6, \mathrm{P}=0.005, \mathrm{I}^{2}=68 \%$

Test for overall effect: $z=4.47, P<0.001$

\section{Lidocaine $\mathbf{2 5 0} \mathbf{~ m g}$ pretreatment}

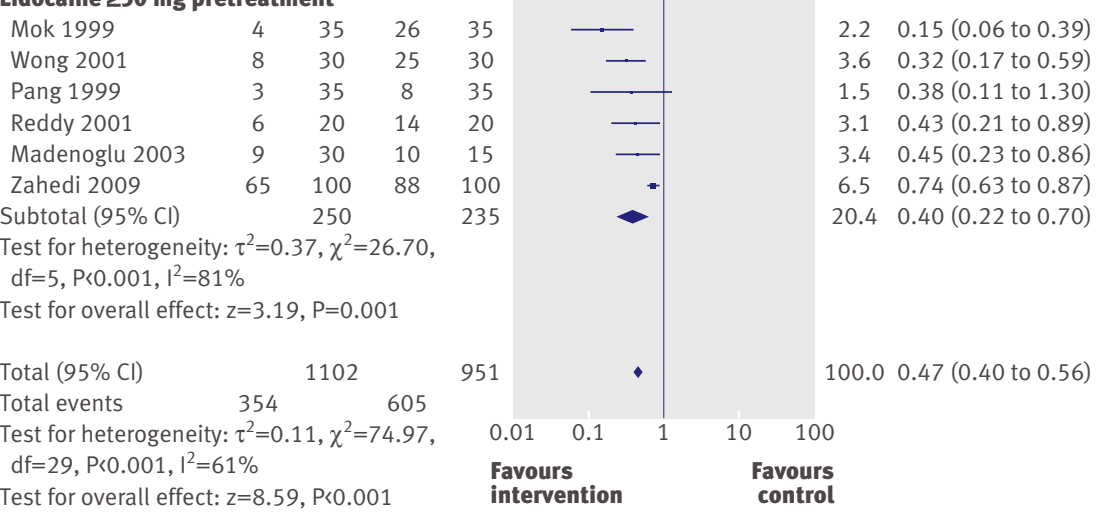

Fig 5 | Effect of pretreatment with lidocaine on risk of pain from propofol injection

Pretreatment with opioids showed analgesic benefit $(0.49,0.41$ to 0.59 , fig 6$)$. Various opioids were studied: alfentanil (six studies), ${ }^{179-184}$ remifentanil $(n=5),{ }^{185-189}$ sufentanil $(\mathrm{n}=1),{ }^{187}$ fentanyl $(\mathrm{n}=3),{ }^{180} 185190$ tramadol $(\mathrm{n}=3),{ }^{70} 161163$ meperidine (pethidine) $(\mathrm{n}=3),{ }^{161} 173186$ and butorphanol $(n=1) .{ }^{191}$ All of these opioids were successful in reducing pain from propofol injection.

Pretreatment with the N-methyl-D-aspartic acid antagonist ketamine was also effective in reducing the risk of pain from propofol injection $(0.52,0.46$ to 0.57 , fig 7). ${ }^{164168192-196}$

Pretreatment with non-steriodal anti-inflammatory drugs was also effective in seven trials $(0.67,0.49$ to
0.91, fig 8). Flurbiprofen, diclofenac, and ketorolac were the primary agents explored for potential reduction of pain from propofol injection. ${ }^{147177 \text { 197-201 }}$

Modified propofol formulations containing medium and long chain triglycerides compared with formulations containing long chain triglycerides were effective in 24 trials $\left(0.75,0.67\right.$ to 0.84 , fig 9). ${ }^{56151177197202-219}$ Combining trials that studied various combinations of standard and modified emulsion formulations with lidocaine had a similar effect $(0.61,0.44$ to 0.84). ${ }^{149151203206220-227}$

\section{Combined drug and non-drug category}

The combined drug and non-drug category incorporated non-drug techniques such as site of injection, ${ }^{119123124126}$ alteration of temperature of propofol,, 90132133135 and venous occlusion (table 4). The most commonly studied intervention was venous occlusion in conjunction with various drugs, such as antiemetics, non-steroidal anti-inflammatory drugs, $\beta$ blockers, lidocaine, and opioids; many combinations reduced the risk of pain from propofol injection. In this category pretreatment using lidocaine in conjunction with venous occlusion was the most effective intervention at preventing the pain from propofol injection $\left(0.29,0.22\right.$ to 0.38 , fig 10). ${ }^{133142152177228-236}$ One trial found that lidocaine applied ionophoretically was more effective than a sham application $(0.31,0.14$ to 0.69). ${ }^{237}$ Three trials found statistically significant results with modifications of propofol's temperature in combination with drugs such as lidocaine and nafamostat. ${ }^{132} 133136$

\section{Risk of bias assessment}

Eight interventions statistically significantly reduced the pain from propofol injection. A sensitivity analysis to assess the potential effect of four criteria for the risk of bias assessment was carried out. When the point estimates or confidence intervals of the individual domains were compared with the overall point estimates, no appreciable difference occurred that would change the interpretation of the results (table 5).

\section{Indirect comparisons}

To be able to rank the interventions, a network approach was used to estimate indirect comparisons among effective interventions involving more than six studies. ${ }^{11}$ Indirect treatment comparisons were estimated for the eight pairwise (intervention versus control) statistically significant interventions; the data were derived from 167 treatment arms in 101 studies. These eight interventions were included as moderators in a mixed effects metaregression (table 6). An omnibus test for inclusion of the moderators was significant $\left(\mathrm{F}=46.5_{8},{ }_{159}, \mathrm{P}<0.001\right)$ and each individual regression coefficient was significant ( $\mathrm{t}$ statistics, $\mathrm{P}<0.05$ for all interventions). While the residual heterogeneity $\left(\tau^{2}=0.10\right)$ remained significant $\left(\chi^{2}=402, \quad \mathrm{df}=159\right.$, $\mathrm{P}<0.001)$, about $44 \%$ of the residual heterogeneity had been accounted for by the inclusion of the eight 


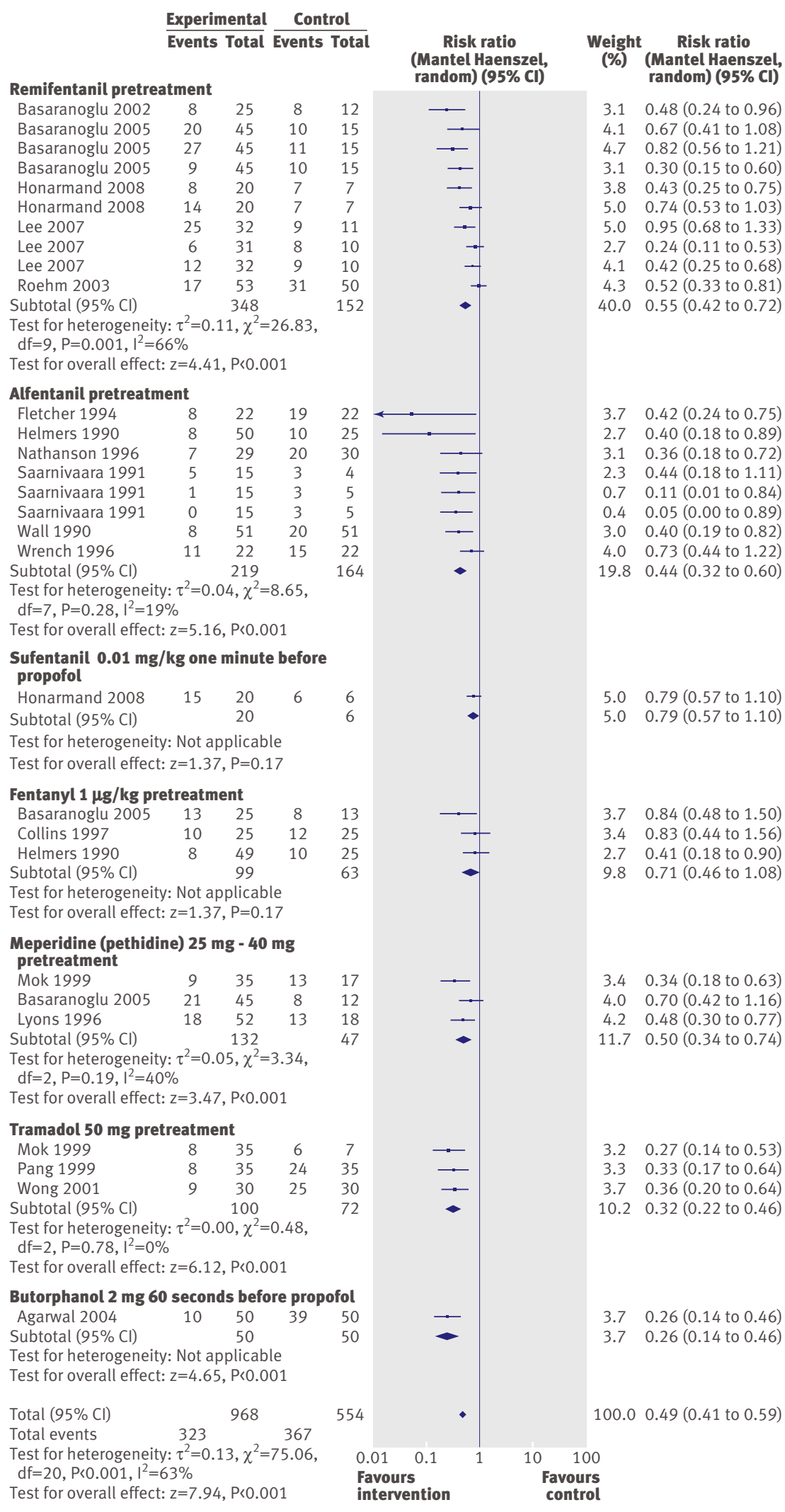

Fig 6 | Effect of pretreatment with opioids on risk of pain from propofol injection moderators in the model; the Akaike information criterion was also reduced in the full model.

The relative risk of using an antecubital vein was lower than for six of the other interventions, with the indirect relative risks ranging from 0.19 (modified propofol formulation) to 0.34 (lidocaine-propofol admixture). Pretreatment using lidocaine in conjunction with venous occlusion also had a lower relative risk than six of the other interventions, with the indirect relative risks ranging from 0.39 (modified propofol formulation) to 0.69 (lidocaine-propofol admixture). Although the indirect relative risk for using an antecubital vein compared with pretreatment using lidocaine in conjunction with venous occlusion was 0.50 , the $95 \%$ confidence interval extended beyond the identity line.

The risk of pain was similarly reduced for five interventions (lidocaine-propofol admixture, and pretreatment with lidocaine, opioids, ketamine, and nonsteroidal anti-inflammatory drugs), with direct relative risks varying from 0.43 to 0.67 . Confidence intervals for nine of the 10 indirect relative risks between the five interventions were non-significant (table 6). Six interventions had lower indirect relative risks compared with a modified propofol formulation.

\section{DISCUSSION}

About $60 \%$ of patients experience pain on injection with standard propofol alone - that is, without any preventive measures. A previous systematic review and meta-analysis identified pretreatment using lidocaine (lignocaine) in conjunction with venous occlusion using a tourniquet to be the most efficacious intervention to reduce pain from propofol injection. ${ }^{2}$ Since then more than 100 randomised controlled trials have been published on the topic. Our systematic review and meta-analysis confirms the efficacy of the previously suggested technique (relative risk 0.29). However, selecting an antecubital vein instead of a hand vein was numerically the most efficacious intervention (relative risk 0.14). In addition, we identified six other efficacious interventions that are commonly used-namely, lidocaine-propofol admixture; pretreatment using lidocaine (without venous occlusion), opioids, non-steroidal anti-inflammatory drugs, or ketamine; and a propofol emulsion containing medium and long chain triglycerides. Furthermore, we carried out indirect comparisons across the meta-analyses and found that choosing the antecubital vein and venous occlusion along with pretreatment using lidocaine were similarly efficacious and clearly superior to the other six interventions.

The results of this analysis show that injection of propofol through an antecubital vein is one of the most effective interventions to reduce associated pain. From a physiological standpoint, differences in vein diameter, flow rate, and endothelial structure might account for the reduction in pain. Presuming that propofol is injected mid-stream into the lumen of the vein, the larger diameter of and faster flow rate through the antecubital vein will minimise the extent to which a high concentration of propofol comes into contact 


\section{Experimental Control}

$\overline{\text { Events Total Events Total }}$

\section{Ketamine 0.75 mg - 3.75 mg}

pretreatment (low dose)

$\begin{array}{lrcc}\text { Koo } 2006 & 19 & 30 & 7 \\ \text { Koo } 2006 & 19 & 30 & 7 \\ \text { Zahedi } 2009 & 60 & 100 & 29 \\ \text { Subtotal }(95 \% \mathrm{Cl}) & & 160 \\ \text { Test for heterogeneity: } \chi^{2}=0.12, \mathrm{df}=2 \text {, } \\ \text { P=0.94, }\left.\right|^{2}=0 \% \\ \text { Test for overall effect: } \mathrm{z}=4.36, P<0.001\end{array}$

\section{Ketamine 5 mg - 20 mg}

pretreatment (moderate dose)

Honarmand $2008 \quad 14 \quad 50 \quad 44$

Koo $2006 \quad 20 \quad 30 \quad 6$

Koo 2006

Suzuki 2002

Tan 1998

Tarmizi 2009

Zahedi 2009

Zahedi 2009

Subtotal $(95 \% \mathrm{Cl})$

$14 \quad 30$

$7 \quad 21$

$$
1350
$$

$20 \quad 36$

55100

$45 \quad 100$

Test for heterogeneity: $\chi^{2}=20.41, \mathrm{df}=7$,

$\mathrm{P}=0.005, \mathrm{I}^{2}=66 \%$

Test for overall effect: $z=10.56, P<0.001$

\section{Ketamine 35 mg - 75 mg}

pretreatment (high dose)

$\begin{array}{lrrr}\text { Iwata } 2010 & 0 & 15 & 7 \\ \text { Iwata } 2010 & 7 & 15 & 7 \\ \text { Subtotal }(95 \% \mathrm{Cl}) & & 30 \\ \text { Test for heterogeneity: } \chi^{2}=7.09, \mathrm{df}=1 \text {, } \\ \text { P=0.008, I }=86 \% \\ \text { Test for overall effect: } z=3.98, P<0.001\end{array}$

Test for overall effect: $z=3.98, P<0.001$

\begin{tabular}{llll} 
Total $(95 \% \mathrm{Cl})$ & \multicolumn{3}{c}{607} \\
Total events & 293 & & 262
\end{tabular}

Test for heterogeneity: $\chi^{2}=35.12, \mathrm{df}=12$, $\mathrm{P}<0.001, \mathrm{I}^{2}=66 \%$

Test for overall effect: $z=12.13, P<0.001$

Test for subgroup differences: Not applicable

Fig 7| Effect of pretreatment with ketamine on risk of pain from propofol injection

with the sensitive endothelial wall. Alternatively, propofol may be buffered more effectively when more blood is available to dissipate and mask the "full effect" of the bolus. Additionally, the composition of nociceptors along the endothelial wall might differ between the smaller veins of the hand and the larger antecubital veins. ${ }^{119139238239}$ In contrast to careful selection of veins, other non-drug interventions-for example, both cold and warm propofol, adjusting the speed of intravenous carrier fluid, and microfiltration-were disappointingly ineffective approaches for alleviating pain from propofol injection.

The other similarly effective intervention was a combination of a drug and non-drug techniques - that is, pretreatment using lidocaine in conjunction with venous occlusion before injection. Although this has been considered the most efficacious technique, it has not become standard. ${ }^{2}$ A reason for this may be the additional procedural steps involved in the intervention, leading to some delay when swift induction is expected. In addition, venous occlusion has also been paired with many other drugs (for example, antiemetics, non-steroidal anti-inflammatory drugs, opioids) and was found to have some measurable success, albeit less so than when venous occlusion was combined with pretreatment using lidocaine. Although some of these combinations of interventions reached statistical significance, they were generally only investigated in a few studies, which makes it difficult to draw meaningful conclusions.

Although pretreatment of a hand vein using lidocaine in conjunction with proximal venous occlusion seems as effective as using an antecubital vein, clinicians may prefer the antecubital vein because it is an effective route and simple to use.

Similarly, of the drug interventions, a lidocaine-propofol admixture was similarly efficacious when compared with pretreatment using lidocaine alone. Both interventions were, however, considerably less efficacious than pretreatment with lidocaine in conjunction with venous occlusion. Interestingly, in the newer studies a trend was towards using a lidocaine-propofol admixture as opposed to propofol alone as the control group, suggesting that this clinical practice has become widely spread. Additionally, the funnel plot for the lidocaine-propofol admixture showed significant asymmetry (fig 4). ${ }^{10240}$ Although this intervention with lidocaine may be efficacious, its treatment effect may be well overestimated.

Our analysis of almost 1500 patients showed that pretreatment with opioids resulted in a relative risk of about 0.50 . Thus, unless contraindicated otherwise, it seems reasonable to use opioids as standard pretreatment several minutes before induction.

Multiple trials investigated a variety of propofol formulations, such as lipid-free formulations, modified emulsion formulations, and propofol containing bismuth. Of these, the most commonly studied emulsions, those containing medium and long chain triglycerides, were compared with the conventional emulsions containing long chain triglyceride (2344 patients, 24 studies), with a relative risk of 0.75 for emulsions containing medium and long chain triglycerides.

Other promising drug interventions were pretreatment with ketamine and with non-steroidal antiinflammatory drugs. Pretreatment with either of these drugs should not only decrease the pain from propofol injection but also reduce postoperative pain, postoperative nausea and vomiting, and the need for postoperative opioids. ${ }^{241242}$ However, diclofenac sodium is itself associated with pain on injection, which may lead to thrombophlebitis. ${ }^{62243}$ Although this may be avoided by using a newer formulation, dilution, or slow intravenous infusion, the pain on injection using diclofenac limits its use for reducing the pain from propofol injection. 


\section{Experimental Control}

$\overline{\text { Events Total Events Total }}$

Flurbiprofen $10 \mathrm{mg}$ - $50 \mathrm{mg}$ pretreatment

$\begin{array}{lcccc}\text { Nishiyama 2005 } & 0 & 50 & 21 & 25 \\ \text { Oka 2008 } & 8 & 20 & 14 & 20 \\ \text { Karasawa 2000 } & 28 & 50 & 25 & 50 \\ \text { Nishiyama 2005 } & 22 & 50 & 20 & 25 \\ \text { Subtotal }(95 \% \mathrm{Cl}) & & 170 & & 120\end{array}$

Test for heterogeneity: $\tau^{2}=0.46, \chi^{2}=22.15$,

$\mathrm{df}=3, \mathrm{P}<0.001, \mathrm{I}^{2}=86 \%$

Test for overall effect: $z=1.52, P=0.13$

Diclofenac 15 mg - 25 mg pretreatment

$\begin{array}{lllll}\text { Mohta 2004 } & 21 & 40 & 15 & 20 \\ \text { Mohta 2004 } & 28 & 40 & 15 & 20\end{array}$

Subtotal $(95 \% \mathrm{Cl}) \quad 80 \quad 40$

Test for heterogeneity: $\tau^{2}=0.01, \chi^{2}=1.26$,

$\mathrm{df}=1, \mathrm{P}=0.26, \mathrm{I}^{2}=20 \%$

Test for overall effect: $z=1.34, P=0.18$

\section{Ketorolac 10 mg - 30 mg pretreatment}

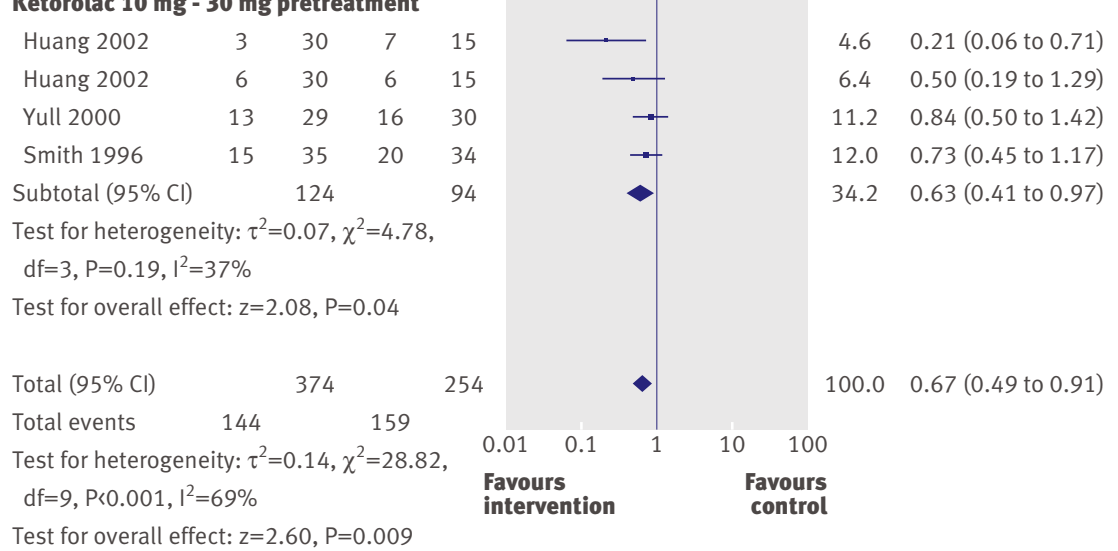

Fig 8 Effect of pretreatment with non-steroidal anti-inflammatory drugs on risk of pain from propofol injection

\section{Clinical implications}

Based on the comparisons carried out here, it seems that among the wide arrays of interventions tested, eight had sufficient evidence of benefit. When interventions seem similarly efficacious, choices for intervention can be made on factors such as cost, personal choice, and simplicity of application.

Our results of direct and indirect comparisons suggest a possible strategy that is both efficacious and easy to apply in clinical practice (fig 11). Since opioids are used commonly as part of a balanced anaesthesia protocol, it seems reasonable to use them as routine premedication in preparation for induction for all three options, as they halve the risk of pain from propofol injection (relative risk 0.50 ). We do not recommend the use of non-steroidal anti-inflammatory drugs as the results for these agents were heterogeneous and some themselves cause pain on injection. One approach could be to use an antecubital vein, whenever practicable, with its relative risk reduction of about $85 \%$. Based on the assumption that interventions of independent pathways work independently, ${ }^{244}$ the risk of pain on injection is likely to be only $5 \%$ when preoperative opioids are combined with the antecubital approach $(60 \% \times 0.49 \times 0.14=4.1 \%)$. In other words, further interventions are unlikely to benefit more than 1 out of 20 patients, thereby additional interventions would only provide limited additional benefit from a clinical standpoint.

As an intravenous line in the antecubital vein may be occluded when the elbow is flexed, unintentional extravasations may not be detected as quickly as when the dorsum of the hand is used. Therefore when intravenous placement into the antecubital vein is challenging, we consider a fair alternative to be the hand vein with preoperative opioids plus lidocaine in conjunction with venous occlusion as this would also bring the risk down to less than $10 \%(60 \% \times 0.49 \times 0.29=8.5 \%)$. Notably, a lidocaine-propofol admixture was also statistically significantly superior to placebo and is probably the most commonly used approach to reduce the pain from propofol injection. Owing to possible publication bias, however, the "true treatment effect" is unclear so we prefer similarly efficacious methods that have no evidence of publication bias. The other practical alternative could be to use preoperative opioids in

Table 5 | Sensitivity analysis to assess potential effect of four criteria for risk of bias assessment in studies with statistically significant results for interventions to reduce the pain from propofol injection

\begin{tabular}{|c|c|c|c|c|c|}
\hline \multirow[b]{2}{*}{ Intervention } & \multirow[b]{2}{*}{$\begin{array}{l}\text { Overall relative risk ( } 95 \% \\
\mathrm{CI} \text { ) (No of studies) }\end{array}$} & \multicolumn{4}{|c|}{ Relative risk* $(95 \% \mathrm{Cl})$ (No of studies) } \\
\hline & & Sequence generation & Allocation concealment & Blinding & $\begin{array}{l}\text { Completeness of outcome } \\
\text { data reported }\end{array}$ \\
\hline Antecubital versus hand vein & $0.14(0.07$ to 0.30$)(6)$ & $0.14(0.05$ to 0.36$)(1)$ & $0.18(0.07$ to 0.46$)(4)$ & 0.05 (0.00 to 0.79$)(1)$ & $0.14(0.07$ to 0.30$)(6)$ \\
\hline Lidocaine pretreatment+venous occlusion & $0.29(0.22$ to 0.38$)(14)$ & $0.27(0.19$ to 0.37$)(9)$ & $0.27(0.20$ to 0.35$)(11)$ & $0.29(0.22$ to 0.39$)(13)$ & $0.27(0.21$ to 0.35$)(13)$ \\
\hline Lidocaine-propofol admixture & $0.40(0.33$ to 0.48$)(25)$ & $0.45(0.31$ to 0.64$)(7)$ & $0.45(0.31$ to 0.64$)(7)$ & $0.41(0.33$ to 0.50$)(19)$ & $0.41(0.33$ to 0.50$)(20)$ \\
\hline Lidocaine pretreatment & $0.47(0.40$ to 0.56$)(24)$ & $0.39(0.29$ to 0.53$)(9)$ & $0.44(0.32$ to 0.60$)(10)$ & $0.44(0.35$ to 0.56$)(16)$ & $0.52(0.43$ to 0.61$)(21)$ \\
\hline Opioid pretreatment & 0.49 (0.41 to 0.59$)(17)$ & $0.47(0.34$ to 0.66$)(6)$ & $0.47(0.34$ to 0.66$)(6)$ & 0.50 (0.41 to 0.59$)(16)$ & $0.48(0.40$ to 0.58$)(16)$ \\
\hline Ketamine pretreatment & $0.56(0.47$ to 0.67$)(7)$ & $0.34(0.15$ to 0.74$)(3)$ & $0.34(0.15$ to 0.74$)(1)$ & $0.52(0.46$ to 0.57$)(7)$ & $0.55(0.45$ to 0.69$)(5)$ \\
\hline NSAID pretreatment & $0.67(0.49$ to 0.91$)(7)$ & $0.57(0.36$ to 0.91$)(4)$ & $0.57(0.36$ to 0.91$)(5)$ & $0.79(0.62$ to 1.01$)(5)$ & $0.67(0.41$ to 0.97$)(7)$ \\
\hline $\begin{array}{l}\text { Emulsion of medium and long chain } \\
\text { trigylcerides } v \text { long chain triglycerides }\end{array}$ & 0.75 (0.67 to 0.84$)(24)$ & 0.85 (0.67 to 1.06$)(11)$ & 0.84 (0.68 to 1.04$)(12)$ & $0.76(0.68$ to 0.84$)(21)$ & 0.73 (0.64 to 0.83$)(21)$ \\
\hline
\end{tabular}




\section{Experimental Control}

\section{Events Total Events Total}

Propofol emulsions medium and long chain triglycerides $\boldsymbol{v}$ long chain triglycerides (control)

$\begin{array}{lcccc}\text { Allford 2006 } & 36 & 60 & 46 & 60 \\ \text { Bachmann } & 53 & 112 & 65 & 110 \\ \text {-Mennenga 2007 } & & & & \\ \text { Doenicke 1997 } & 7 & 12 & 9 & 12 \\ \text { Doenicke 1997 } & 11 & 12 & 11 & 12 \\ \text { Knibbe 1999 } & 0 & 8 & 1 & 4 \\ \text { Knibbe 1997 } & 2 & 8 & 1 & 4 \\ \text { Kunitz 2004 } & 8 & 20 & 10 & 20 \\ \text { Larsen 2001 } & 34 & 92 & 59 & 92 \\ \text { Lassnigg 2003 } & 17 & 30 & 23 & 29 \\ \text { Liljeroth 2005 } & 38 & 73 & 52 & 73 \\ \text { Mallick 2007 } & 49 & 81 & 59 & 82 \\ \text { Nagao 2005 } & 49 & 99 & 58 & 95 \\ \text { Nishlyama 2005 } & 15 & 50 & 41 & 50 \\ \text { Ohmizo 2005 } & 36 & 98 & 63 & 102 \\ \text { Oka 2008 } & 7 & 20 & 14 & 20 \\ \text { Paul 2003 } & 12 & 15 & 3 & 15 \\ \text { Rau 2001 } & 28 & 74 & 46 & 75 \\ \text { Sim 2009 } & 30 & 71 & 53 & 76 \\ \text { Song 2004 } & 12 & 31 & 3 & 32 \\ \text { Song 2004 } & 16 & 31 & 8 & 29 \\ \text { Sundarathiti 2007 } & 41 & 55 & 54 & 55 \\ \text { Suzuki 2006 } & 11 & 22 & 20 & 23 \\ \text { Ueki 2007 } & 29 & 50 & 35 & 50 \\ \text { Weksler 2001 } & 11 & 30 & 13 & 30 \\ \text { Yamakage 2005 } & 8 & 20 & 13 & 20 \\ \text { Subtotal (95\% CI) } & & 1174 & & 117 \\ \text { Total events } & 560 & & 760 & \end{array}$

Test for heterogeneity: $\tau^{2}=0.04, \chi^{2}=55.69$, $d f=24, P<0.001, I^{2}=57 \%$

Test for overall effect: $z=4.94, P<0.001$

Test for subgroup differences: Not applicable
Risk ratio (Mantel Haenszel random) $(95 \% \mathrm{Cl})$ .



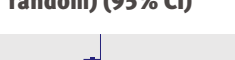

\section{Weight
(\%) $\begin{gathered}\text { Risk ratio } \\ \text { (Mantel Haenszel, }\end{gathered}$ random) $(95 \% \mathrm{Cl})$}

6.20 .78 (0.61 to 1.00$)$

6.20 .80 (0.62 to 1.03$)$

$2.7 \quad 0.78$ (0.44 to 1.39$)$

6.31 .00 (0.79 to 1.27$)$

$0.1 \quad 0.19$ (0.01 to 3.75)

$0.31 .00(0.13$ to 8.00$)$

2.10 .80 (0.40 to 1.60$)$

$5.4 \quad 0.58$ (0.42 to 0.78$)$

$4.7 \quad 0.71$ (0.50 to 1.03$)$

$6.0 \quad 0.73$ (0.56 to 0.95$)$

$6.6 \quad 0.84$ (0.67 to 1.05$)$

$6.1 \quad 0.81$ (0.63 to 1.05$)$

3.80 .37 (0.23 to 0.57$)$

5.40 .59 (0.44 to 0.80$)$

$2.2 \quad 0.50$ (0.26 to 0.97$)$

1.14 .00 (1.41 to 11.35$)$

4.90 .62 (0.44 to 0.87 )

$5.3 \quad 0.61$ (0.44 to 0.83 )

$0.9 \quad 4.13$ (1.29 to 13.23$)$

$2.2 \quad 1.87$ (0.95 to 3.70$)$

$\begin{array}{ll}7.5 & 0.76(0.65 \text { to } 0.89)\end{array}$

3.80 .57 (0.37 to 0.90)

5.50 .83 (0.62 to 1.12$)$

$2.5 \quad 0.85$ (0.45 to 1.58$)$

$2.4 \quad 0.62$ (0.33 to 1.15$)$

$100.0 \quad 0.75(0.67$ to 0.84$)$
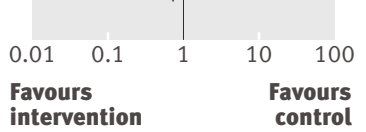

conjunction with pretreatment using lidocaine or ketamine before the injection of a propofol emulsion containing medium and long chain triglycerides, thereby also reducing the risk of pain to about $10-12 \% \quad(60 \% \times 0.49 \times 0.47 \times 0.75=10.3 \%) \quad$ or $\quad 12 \%$ $(60 \% \times 0.49 \times 0.56 \times 0.75=12.3 \%)$. Nevertheless, these estimates of multiplicative treatment effects are based on the assumption of independence and strictly speaking require confirmation in randomised controlled trials.

\section{Limitations of the study}

A range of other techniques reached statistical significance in a limited number of studies (often only one or two) and some of them lacked biological plausibility, such as the efficacy reported for antiemetics, cholinesterase inhibitors, antihistamines, stimulants, and combinations of interventions. Further research is needed to verify or refute these results and, if these interventions are truly efficacious, it will be essential to uncover underlying mechanisms. Furthermore, assessment of the intensity of pain score as an additional outcome was unachievable.

\section{Conclusions}

Unless contraindicated we recommend the routine use of a small dose of opioids before induction of anaesthesia using propofol injection in all patients. On the basis of efficacy and convenience we also recommend using an antecubital vein instead of a hand vein. If the hand vein is the site of injection, we recommend pretreatment using lidocaine in conjunction with venous occlusion, or a combined intervention such as pretreatment with ketamine or lidocaine before injection of a propofol emulsion containing medium and long chain triglycerides.

Fig 9 | Effect of propofol emulsions containing medium and long chain triglycerides compared with those containing long chain trigylcerides on risk of pain from propofol injection

Table 6 | Indirect comparisons between efficacious interventions to reduce pain from propofol injection

\begin{tabular}{|c|c|c|c|c|c|c|c|}
\hline \multirow[b]{2}{*}{ Intervention $v$ control } & \multicolumn{7}{|c|}{ Relative risk $(95 \% \mathrm{Cl})$} \\
\hline & Antecubital vein & $\begin{array}{l}\text { Lidocaine } \\
\text { pretreatment+venous } \\
\text { occlusion }\end{array}$ & $\begin{array}{l}\text { Lidocaine } \\
\text { combination }\end{array}$ & $\begin{array}{l}\text { Lidocaine } \\
\text { pretreatment }\end{array}$ & $\begin{array}{l}\text { Opioids } \\
\text { pretreatment }\end{array}$ & $\begin{array}{c}\text { Ketamine } \\
\text { pretreatment }\end{array}$ & $\begin{array}{c}\text { NSAID } \\
\text { pretreatment }\end{array}$ \\
\hline Antecubital vein $0.15(0.07 \text { to } 0.33)^{\star \star \star}$ & 1.00 & - & - & - & - & - & - \\
\hline $\begin{array}{l}\text { Lidocaine pretreatment+venous } \\
\text { occlusion } 0.29(0.22 \text { to } 0.39)^{\star \star \star}\end{array}$ & $0.50(0.22$ to 1.16$)$ & 1.00 & - & - & - & - & - \\
\hline $\begin{array}{l}\text { Lidocaine-propofol admixture } 0.43 \\
(0.37 \text { to } 0.50)^{\star \star \star}\end{array}$ & $0.34(0.15 \text { to } 0.77)^{\star}$ & $0.69(0.50 \text { to } 0.94)^{*}$ & 1.00 & - & - & - & - \\
\hline $\begin{array}{l}\text { Lidocaine pretreatment } 0.47 \\
(0.39 \text { to } 0.57)^{\star \star \star}\end{array}$ & $0.32(0.14 \text { to } 0.71)^{\star *}$ & $0.63(0.45 \text { to } 0.88)^{\star *}$ & $0.92(0.72$ to 1.17$)$ & 1.00 & - & - & - \\
\hline $\begin{array}{l}\text { Opioid pretreatment } 0.51 \\
(0.42 \text { to } 0.61)^{\star \star \star}\end{array}$ & $0.29(0.13 \text { to } 0.66)^{\star \star}$ & $0.58(0.42 \text { to } 0.81)^{\star \star}$ & 0.85 (0.66 to 1.08$)$ & $0.92(0.71$ to 1.20$)$ & 1.00 & - & - \\
\hline $\begin{array}{l}\text { Ketamine pretreatment } 0.55 \\
(0.44 \text { to } 0.70)^{\star \star \star}\end{array}$ & $0.27(0.12 \text { to } 0.61)^{\star *}$ & $0.53(0.37 \text { to } 0.77)^{\star \star \star *}$ & 0.78 (0.59 to 1.03$)$ & 0.85 (0.63 to 1.15$)$ & 0.92 (0.68 to 1.24$)$ & 1.00 & - \\
\hline NSAID pretreatment $0.67(0.49 \text { to } 0.91)^{*}$ & $0.22(0.10 \text { to } 0.52)^{\star \star \star}$ & $0.44(0.29 \text { to } 0.66)^{\star \star \star \star}$ & $0.64(0.45 \text { to } 0.90)^{\star}$ & 0.70 (0.49 to 1.00$)$ & $0.76(0.53$ to 1.08$)$ & $0.82(0.56$ to 1.21$)$ & 1.00 \\
\hline $\begin{array}{l}\text { Emulsions with medium and long chain } \\
\text { triglycerides } v \text { long chain triglycerides } \\
0.76(0.64 \text { to } 0.91)^{\star \star}\end{array}$ & $0.19(0.09 \text { to } 0.44)^{\star \star \star}$ & $0.39(0.28 \text { to } 0.53)^{\star \star \star \star}$ & $0.56(0.44 \text { to } 0.71)^{\star \star \star}$ & $0.61(0.47 \text { to } 0.79)^{\star \star \star}$ & $0.66(0.51 \text { to } 0.86)^{\star \star}$ & $0.72(0.54 \text { to } 0.97)^{\star}$ & 0.88 (0.62 to 1.25$)$ \\
\hline
\end{tabular}

NSAID=non-steroidal anti-inflammatory drug.

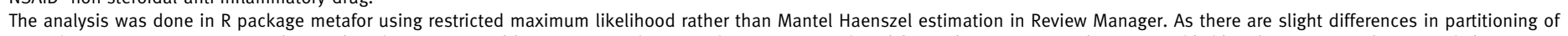
control group event rates to avoid unit of analysis errors and because Mantel Haenszel estimation is closed form whereas restricted maximum likelihood is iterative, there are slight differences of the direct relative risks from values displayed in table 1 .

${ }^{\star} \mathrm{P}<0.05 ;{ }^{* *} \mathrm{P}<0.01 ;{ }^{* *} \mathrm{P}<0.001$. 


\begin{tabular}{|c|c|c|c|c|c|c|c|c|}
\hline \multirow{2}{*}{ Lidocaine $20 \mathrm{mg}$ wi } & \multicolumn{2}{|c|}{ Experimental } & \multicolumn{2}{|c|}{ Control } & \multirow{2}{*}{\multicolumn{2}{|c|}{$\begin{array}{c}\text { Risk ratio } \\
\text { (Mantel Haenszel, } \\
\text { random) }(95 \% \mathrm{Cl})\end{array}$}} & \multirow[b]{2}{*}{$\begin{array}{l}\text { Weight } \\
\text { (\%) }\end{array}$} & \multirow[b]{2}{*}{$\begin{array}{c}\text { Risk ratio } \\
\text { (Mantel Haenszel, } \\
\text { random) }(95 \% \mathrm{Cl})\end{array}$} \\
\hline & $\begin{array}{l}\text { Events } \\
\text { vith ven } \\
\text { ed by pr }\end{array}$ & $\begin{array}{l}\text { Total } \\
\text { us occ } \\
\text { pofol }\end{array}$ & \multicolumn{2}{|c|}{$\begin{array}{l}\text { Events Total } \\
\text { clusion for } 20-60 \\
2-2.5 \mathrm{mg} / \mathrm{kg}\end{array}$} & & & & \\
\hline Asik 2003 & 5 & 30 & 28 & 30 & \multirow{2}{*}{ 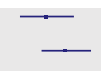 } & & 6.2 & $0.18(0.08$ to 0.40$)$ \\
\hline Goldmann 1997 & 6 & 25 & 19 & 25 & & & 6.8 & $0.32(0.15$ to 0.66$)$ \\
\hline Alyafi 1996 & 6 & 25 & 20 & 25 & - & & 6.9 & 0.30 (0.15 to 0.62$)$ \\
\hline Kwak 2008 & 12 & 35 & 31 & 35 & - & & 9.5 & 0.39 (0.24 to 0.62$)$ \\
\hline Subtotal $(95 \% \mathrm{Cl})$ & & 115 & & 115 & $\bullet$ & & 29.4 & 0.31 (0.23 to 0.43$)$ \\
\hline \multicolumn{9}{|c|}{$\begin{array}{l}\text { Test for heterogeneity: } \tau^{2}=0.00, \chi^{2}=2.78, d f=3 \text {, } \\
P=0.43,\left.\right|^{2}=0 \%\end{array}$} \\
\hline \multicolumn{9}{|c|}{ Test for overall effect: $z=7.10, P<0.001$} \\
\hline \multicolumn{9}{|c|}{$\begin{array}{l}\text { Lidocaine } 40 \mathrm{mg} \text { with venous occlusion } \\
\text { followed by propofol } 2.5 \mathrm{mg} / \mathrm{kg}\end{array}$} \\
\hline Oka 2008 & 1 & 20 & 14 & 20 & - & & 1.8 & 0.07 (0.01 to 0.49$)$ \\
\hline Canbay 2008 & 4 & 50 & 32 & 50 & - & & 5.0 & 0.13 (0.05 to 0.33$)$ \\
\hline Liaw 1999 & 4 & 35 & 27 & 35 & - & & 5.2 & 0.15 (0.06 to 0.38$)$ \\
\hline Batra 2005 & 5 & 50 & 40 & 50 & - & & 5.9 & $0.13(0.05$ to 0.29$)$ \\
\hline Massad 2006 & 7 & 50 & 35 & 50 & - & & 7.0 & 0.20 (0.10 to 0.41$)$ \\
\hline Dubey 2003 & 9 & 50 & 31 & 50 & - & & 7.8 & 0.29 (0.15 to 0.55$)$ \\
\hline Saadawy 2007 & 9 & 25 & 22 & 25 & $\rightarrow$ & & 8.7 & 0.41 (0.24 to 0.70$)$ \\
\hline Borazan 2010 & 13 & 50 & 38 & 50 & - & & 9.3 & 0.34 (0.21 to 0.56$)$ \\
\hline $\begin{array}{l}\text { Agarwal } 2004 \\
\text { (thiopental) }\end{array}$ & 12 & 31 & 24 & 31 & $\rightarrow$ & & 9.4 & 0.50 (0.31 to 0.81$)$ \\
\hline Piper 2002 & 19 & 50 & 36 & 50 & $\rightarrow$ & & 10.4 & $0.53(0.36$ to 0.78$)$ \\
\hline Subtotal $(95 \% \mathrm{Cl})$ & & 411 & & 411 & $\bullet$ & & 70.6 & 0.27 (0.19 to 0.40$)$ \\
\hline \multicolumn{9}{|c|}{$\begin{array}{l}\text { Test for heterogeneity: } \tau^{2}=0.23, \chi^{2}=29.12 \text {, } \\
d f=9, P<0.001, I^{2}=69 \%\end{array}$} \\
\hline \multicolumn{9}{|c|}{ Test for overall effect: $z=6.77, P<0.001$} \\
\hline Total $(95 \% \mathrm{Cl})$ & & 526 & & 526 & $\bullet$ & & 100.0 & 0.29 (0.22 to 0.38$)$ \\
\hline \multirow{2}{*}{\multicolumn{9}{|c|}{$\begin{array}{l}\text { Test for heterogeneity: } \tau^{2}=0.15, \chi^{2}=31.57 \text {, } \\
d f=13, P=0.003, I^{2}=59 \%\end{array}$}} \\
\hline & & & & & & & & \\
\hline Test for overall eff & ect: $z=8$ & $94, \mathrm{P}$ & & & & & & \\
\hline
\end{tabular}

$\overline{\text { Fig } 10}$ Effect of pretreatment using lidocaine in conjunction with venous occlusion or no venous occlusion on risk of pain from propofol injection

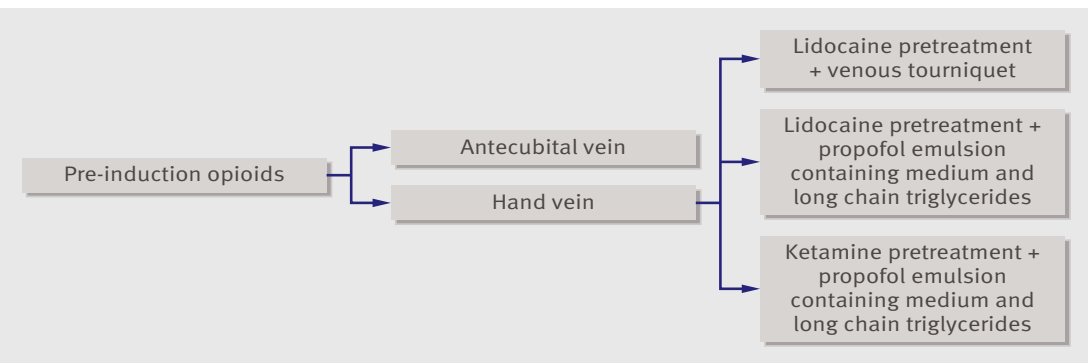

Fig 11| Possible simple strategy to minimise pain from propofol injection

\section{WHAT IS ALREADY KNOWN ON THIS TOPIC}

Pretreatment with lidocaine (lignocaine) in conjunction with venous occlusion has been suggested as the best intervention to reduce pain from propofol injection

This technique failed to gain widespread popularity and the search for alternative interventions continues

\section{WHAT THIS STUDY ADDS}

Using an antecubital vein instead of a hand vein is a simple and effective way to avoid the pain from propofol injection

If the hand vein is chosen, pretreatment using lidocaine in conjunction with venous occlusion is equally efficacious, although not widely used

A third option could be the combination of "less efficacious interventions," such as using a modified propofol emulsion in conjunction with pretreatment of the hand vein using lidocaine or ketamine
We thank Wolfgang Viechtbauer (School for Public Health and Primary Care, Maastricht University, the Netherlands) for the syntax of arguments used in the R package metafor; David Moher (Ottawa Hospital Research Institute, University of Ottawa) for proving critical input for the study; and Sakura Kinjo (University of California San Francisco) for translating the Japanese manuscripts. RevMan 5.0 (Review Manager, Cochrane Collaboration, UK) statistical package was used in this systematic review for analysis. Additionally, the R packages metafor and meta were used ( $R$ Development Core Team (2010). R: A language and environment for statistical computing. R Foundation for Statistical Computing).

Contributors: VK, LJ, YYS, OR, and CCA wrote the study protocol. LJ and VK collected and collated the data. CCA and NLP provided statistical expertise. CCA, LJ, and NLP analysed and interpreted the data. LJ, YYS, $\mathrm{EG}, \mathrm{CH}, \mathrm{CCA}$, and NLP drafted the article. LJ, EG, YYS, CH, CCA, OR, and NLP critically revised the article for important intellectual content. LJ, EG, YYS, CH, CCA, and NLP provided administrative, technical, or logistic support. All authors approved the final article, had full access to all the data (including statistical reports and tables), and can take responsibility for the integrity of the data and the accuracy of the data analysis. CCA, LJ, and NLP are the guarantors.

Funding: This study was funded by the Perioperative Clinical Research Core, University of California, San Francisco.

Competing interests: All authors have completed the Unified Competing Interest form at www.icmje.org/coi_disclosure.pdf and declare that L), VK, EG, YYS, CH, OR, and CCA have support from the Perioperative Clinical Research Core, Department of Anaesthesia and Perioperative Care, University of California, San Francisco, CA for the submitted work: LJ, VK, EG, YYS, CH, NLP, OR, and CCA have no relationships that might have an interest in the submitted work in the previous 3 years; their spouses, partners, or children have no financial relationships that may be relevant to the submitted work; and LJ, VK, EG, YYS, OR, and CCA have no non-financial interests; and NLP is an unpaid statistical editor for a Cochrane Collaborative Review Group.

Ethical approval: Not required.

Data sharing: The technical appendix, statistical code, and dataset are available from the corresponding author at apfelc@anesthesia.ucsf.edu.

1 Marik PE. Propofol: therapeutic indications and side-effects. Curr Pharm Des 2004;10:3639-49.

2 Picard P, Tramer MR. Prevention of pain on injection with propofol: quantitative systematic review. Anesth Analg 2000;90:963-9.

3 Wang H, Cork R, Rao A. Development of a new generation of propofol. Curr Opin Anaesthesiol 2007;20:311-5.

4 Baker MT, Naguib M. Propofol: the challenges of formulation. Anesthesiology 2005;103:860-76.

5 Sim JY, Lee SH, Park DY, Jung JA, Ki KH, Lee DH, et al. Pain on injectio with microemulsion propofol. BrJ Clin Pharmacol 2009;67:316-25.

6 Weksler N, Rozentsveig V, Tarnoploski A, Gurman GM. Commercial propofol solutions: is the more expensive also the more effective? J Clin Anesthesia 2001;13:321-4.

7 Dubey PK, Kumar A. Pain on injection of lipid-free propofol and propofol emulsion containing medium-chain triglyceride: a comparative study. Anesth Analg 2005:101:1060-2.

8 Higgins JPT, Green S, eds. Cochrane handbook for the systematic reviews of interventions. Version 5.0.2. Cochrane Collaboration, 2009.

9 Liberati A, Altman DG, Tetzlaff J, Mulrow C, Gotzsche PC, loannidis JP, et al. The PRISMA statement for reporting systematic reviews and meta-analyses of studies that evaluate healthcare interventions: explanation and elaboration. BMJ 2009;339:b2700.

10 Rucker G, Schwarzer G, Carpenter J. Arcsine test for publication bias in meta-analyses with binary outcomes. Stat Med 2008;27:746-63.

11 Salanti G, Higgins JP, Ades AE, loannidis JP. Evaluation of networks of randomized trials. Stat Methods Med Res 2008;17:279-301.

12 Viechtbauer W. Conducting meta-analyses in R with the metafor package. / Stat Software 2010;36:1-48.

13 Knapp G, Hartung J. Improved tests for a random effects metaregression with a single covariate. Stat Med 2003;22:2693-710.

14 Bryson HM, Fulton BR, Faulds D. Propofol. An update of its use in anaesthesia and conscious sedation. Drugs 1995;50:513-59.

15 Langley MS, Heel RC. Propofol. A review of its pharmacodynamic and pharmacokinetic properties and use as an intravenous anaesthetic. Drugs 1988:35:334-72.

16 Tan CH, Onsiong MK. Pain on injection of propofol. Anaesthesia 1998;53:468-76.

17 Auerswald K, Pfeiffer F, Behrends K, Burkhardt U, Olthoff D. [Pain on injection with propofol.] Anasthesiol Intensivmed Notfallmed Schmerzther 2005;40:259-66. 
18 Egan TD, Kern SE, Johnson KB, Pace NL. The pharmacokinetics and pharmacodynamics of propofol in a modified cyclodextrin formulation (Captisol (registered trademark)) versus propofol in a lipid formulation (Diprivan (registered trademark)): an electroencephalographic and hemodynamic study in a porcine model. Anesth Analg 2003;97:72-9.

19 Eriksson M, Englesson S, Horte I, Hartvig P. The anaesthetic potency of propofol in the rat is reduced by simultaneous intravenous administration of lignocaine. Eur J Anaesthesiol 1999;16:315-9.

20 Aun CS, Short SM, Leung DH, Oh TE. Induction dose-response of propofol in unpremedicated children. Br J Anaesth 1992;68:64-7.

21 Ayuso MA, Luis M, Sala X, Fernandez J, Gomar C. Incidence of pain upon injection of a new formula of propofol in a fat emulsion of medium- and long-chain triglycerides. Revista Espanola de Anestesiologia y Reanimacion 2004;51:531-6.

22 Bachmann-Mennenga B, Ohlmer A, Heesen M. Incidence of pain after intravenous injection of a medium-/long-chain triglyceride emulsion of propofol. An observational study in 1375 patients. Arzneimittelforschung 2003;53:621-6.

23 Borgeat A, Fuchs T, Tassonyi E. Induction characteristics of $2 \%$ propofol in children. Br J Anaesth 1997;78:433-5.

24 Cameron E, Johnston G, Crofts S, Morton NS. The minimum effective dose of lignocaine to prevent injection pain due to propofol in children. Anaesthesia 1992;47:604-6.

25 Cheng KI, Tang CS, Chiu SL, Chen TI, Wang CJ, Fan KT, et al. Injection pain with propofol: the effectiveness of thiopentone on induction. Kaohsiung J Med Sci 1998;14:480-5.

26 Goel AV, Kaul T, Singh A, Grewal A, Singh RM, Kakkar DK. Analgesic effect of lignocaine, tramadol, ketorolac and ketoprofen in ameliorating propofol injection pain. J Anaesth Clin Pharmacol 2005;21:389-93.

27 Hwang J, Park HP, Lim YJ, Do SH, Lee SC, Jeon YT. Preventing pain on injection of propofol: a comparison between peripheral ketamine pre-treatment and ketamine added to propofol. Anaesth Intensive Care 2009;37:584-7.

28 Ishiyama T, Kashimoto S, Oguchi T, Furuya A, Fukushima H, Kumazawa T. Clonidine-ephedrine combination reduces pain on injection of propofol and blunts hemodynamic stress responses during the induction sequence. J Clin Anesth 2006;18:211-5.

29 Kang HJ, Kwon MY, Choi BM, Koo MS, Jang YJ, Lee MA. Clinical factors affecting the pain on injection of propofol. Korean J Anesthesiol 2010;58:239.

30 Liljeroth E, Karlsson A, Lagerkranser M, Akeson J. Sustained intravascular exposure to propofol does not prolong pain at the site of injection. Acta Anaesthesiol Scand 2007;51:456-9.

31 Memis D, Turan A, Karamanlioglu B, Kaya G, Pamukcu Z. The prevention of propofol injection pain by tramadol or ondansetron. Eur / Anaesthesiol 2002;19:47-51.

32 Nieves GB, Avila FR, Arenas CMG. Dolor a la administracion de propofol: comparacion de lidocaina con metoclopramida.J Soc Anest 1997;20:53-6.

33 Rahman Al-Refai A, Al-Mujadi H, Petrova IM, Marzouk HM, Batra YK, et al. Prevention of pain on injection of propofol: a comparison of remifentanil with alfentanil in children. Minerva Anestesiol 2007;73:219-23.

34 Slavik VC, Zed PJ. Combination ketamine and propofol for procedural sedation and analgesia. Pharmacotherapy 2007;27:1588-98.

35 Gold MI, Abraham EC, Herrington C. A controlled investigation of propofol, thiopentone and methohexitone. Can J Anaesth 1987;34:478-83.

36 Kazama T, Ikeda K, Morita K, Kikura M, Ikeda T, Kurita T, et al. Investigation of effective anesthesia induction doses using a wide range of infusion rates with undiluted and diluted propofol. Anesthesiology 2000;92:1017-28.

37 Lembert N, Wodey E, Geslot D, Ecoffey C. Prevention of pain on injection with propofol in children: comparison of nitrous oxide with lidocaine. Ann Fr Anesth Reanim 2002;21:263-70.

38 Ong LB, Plummer JL, Waldow WC, Owen H. Timing of midazolam and propofol administration for co-induction of anaesthesia. Anaesth Intensive Care 2000;28:527-31.

39 Taylor E, Ghouri AF, White PF. Midazolam in combination with propofol for sedation during local anesthesia. J Clin Anesth 1992;4:213-6.

40 Klement W, Arndt JO. Pain on injection of propofol: effects of concentration and diluent. Br J Anaesth 1991;67:281-4.

41 Borgeat A, Wilder-Smith OH, Saiah M, Rifat K. Subhypnotic doses of propofol possess direct antiemetic properties. Anesth Analg 1992;74:539-41.

42 Larsen R, Beerhalter U, Erdkonig R, Larsen B. Propofol in a new formulation (Propofol MCT/LCT): effect on injection pain in children. Anaesthesist 2001;50:676-8.

43 Turan A, Karamanlioglu B, Memis D, Pamukcu Z. Alternative application site of transdermal nitroglycerin and the reduction of pain on propofol injection. Eur J Anaesthesiol 2003;20:170-2.
44 Fujii Y, Numazaki M. Dose-range effects of propofol for reducing emetic symptoms during cesarean delivery. Obstet Gynecol 2002;99:75-9.

45 Fujii Y, Uemura A. Effect of metoclopramide on pain on injection of propofol. Anaesth Intensive Care 2004;32:653-6.

46 Fujii Y, Nakayama M. Reduction of propofol-induced pain through pretreatment with lidocaine and/or flurbiprofen. Clin Drug Investig 2004;24:749-53.

47 Fujii Y. Pretreatment with flurbiprofen axetil and venous occlusion to reduce pain during injection of propofol. Can J Anaesth 2004;51:1047-8.

48 Fujii Y, Nakayama M. A lidocaine/metoclopramide combination decreases pain on injection of propofol. Can J Anaesth 2005;52:474-7.

49 Fujii Y, Shiga Y. Flurbiprofen axetil preceded by venous occlusion in the prevention of pain on propofol injection in the hand: a prospective, randomized, double-blind, vehicle-controlled, dosefinding study in Japanese adult surgical patients. Clin Ther 2005;27:588-93.

50 Fujii Y, Nakayama M. Efficacy of lignocaine plus ketamine at different doses in the prevention of pain due to propofol injection. Clin Drug Investig 2005;25:537-42.

51 Fujii Y, Shiga Y. Age-related differences in metoclopramide requirement for pain on injection of propofol. Clin Drug Investig 2006;26:639-44.

52 Fujii Y, Shiga Y. Influence of aging on lidocaine requirements for pain on injection of propofol. / Clin Anesth 2006;18:526-9.

53 Fujii Y, Nakayama M. Influence of age on flurbiprofen axetil requirements for preventing pain on injection of propofol in Japanese adult surgical patients: a prospective, randomized, double-blind, vehicle-controlled, parallel-group, dose-ranging study. Clin Ther 2006;28:1116-22.

54 Fujii Y, Nakayama M. Prevention of pain due to injection of propofol with IV administration of lidocaine $40 \mathrm{mg}+$ metoclopramide 2.5 , 5, o $10 \mathrm{mg}$ or saline: a randomized, double-blind study in Japanese adult surgical patients. Clin Ther 2007;29:856-61.

55 Fujii Y, Itakura M. Comparison of lidocaine, metoclopramide, and flurbiprofen axetil for reducing pain on injection of propofol in lapanese adult surgical patients: a prospective, randomized, double-blind, parallel-group, placebo-controlled study. Clin Ther 2008;30:280-6.

56 Fujii Y, Itakura M. Pretreatment with flurbiprofen axetil, flurbiprofen axetil preceded by venous occlusion, and a mixture of flurbiprofen axetil and propofol in reducing pain on injection of propofol in adult lapanese surgical patients: a prospective, randomized, doubleblind, placebo-controlled study. Clin Ther 2009;31:721-7.

57 Kallela H, Haasio J, Korttila K. Comparison of eltanolone and propofol in anesthesia for termination of pregnancy. Anesth Analg 1994; 79:512-6

58 Kranke P, Apfel CC, Roewer N, Fujii Y. Reported data on granisetron and postoperative nausea and vomiting by Fujii et al. Are incredibly nice! Anesth Analg 2000;90:1004-7.

59 Fujii Y, Itakura M. A comparison of pretreatment with fentanyl and lidocaine preceded by venous occlusion for reducing pain on injection of propofol: a prospective, randomized, double-blind, placebo-controlled study in adult Japanese surgical patients. Clin Ther 2009;31:2107-12.

60 Ayoglu H, Altunkaya H, Ozer Y, Yapakci O, Cukdar G, Ozkocak I. Does dexmedetomidine reduce the injection pain due to propofol and rocuronium? Eur / Anaesthesiol 2007;24:541-5.

61 Bouvet L, Allaouchiche B, Duflo F, Debon R, Chassard D, Boselli E. Remifentanil is an effective alternative to propofol for patientcontrolled analgesia during digestive endoscopic procedures. Can Anaesth 2004;51:122.

62 Campbell WI, Watters $\mathrm{CH}$. Venous sequelae following IV administration of diclofenac. Br J Anaesth 1989;62:545-7.

63 Heim C, Munzer T, Listyo R. Ondansetron versus droperidol. Postoperative treatment against nausea and vomiting. Comparison of action, adverse effects and acceptance by gynecologic inpatients. Anaesthesist 1994;43:504-9.

64 Kim KM, Choi BM, Park SW, Lee SH, Christensen LV, Zhou J, et al. Pharmacokinetics and pharmacodynamics of propofol microemulsion and lipid emulsion after an intravenous bolus and variable rate infusion. Anesthesiology 2007;106:924

65 Klement W, Arndt JO. Pain on IV injection of some anaesthetic agents is evoked by the unphysiological osmolality or $\mathrm{pH}$ of their formulations. Br J Anaesth 1991;66:189-95.

66 Masago K, Nagata O, Ogura M, Yajima C, Arita H, Hanaoka K. Success rate of anesthesia induction using target-controlled infusion of propofol with fentanyl. Masui 1999;48:256-9.

67 Pang WW, Mok MS, Chang DP, Yang TF, Lin CH, Huang MH Intradermal injection of tramadol has local anesthetic effect: a comparison with lidocaine. Acta Anaesthesiol Sin 1998;36:133-6. 
68 Pang WW, Mok MS, Chang DP, Huang MH. Local anesthetic effect of tramadol, metoclopramide, and lidocaine following intradermal injection. Reg Anesth Pain Med 1998;23:580-3.

69 Pang WW, Mok MS, Huang S, Hwang MH. The analgesic effect of fentanyl, morphine, meperidine, and lidocaine in the peripheral veins: a comparative study. Anesth Analg 1998;86:382-6.

70 Pang WW, Huang PY, Chang DP, Huang MH. The peripheral analgesic effect of tramadol in reducing propofol injection pain: a comparison with lidocaine. Reg Anesth Pain Med 1999;24:246-9.

71 Tramer MR, Glynn C). An evaluation of a single dose of magnesium to supplement analgesia after ambulatory surgery: randomized controlled trial. Anesth Analg 2007;104:1374-9.

72 Wajima Z, Yoshikawa T, Ogura A, Shiga T, Inoue T, Ogawa R. The effects of intravenous lignocaine on haemodynamics and seizure duration during electroconvulsive therapy. Anaesth Intensive Care 2002;30:742-6.

73 Yavascaoglu B, Kaya FN, Ozcan B. Esmolol pretreatment reduces the frequency and severity of pain on injection of rocuronium. / Clin Anesth 2007;19:413-7.

74 Borgeat A, Popovic V, Meier D, Schwander D. Comparison of propofol and thiopental/halothane for short-duration ENT surgical procedures in children. Anesth Analg 1990;71:511-5.

75 Akcaboy ZN, Akcaboy EY, Altinoren B, Karabulut E, Gogus N. Adding remifentanil to propofol and etomidate in cardioversion anesthesia. Saudi Med J 2007;28:1550-4.

76 Arya A, Singh M, Gurwara AK. A comparison of thiopentone sodium, propofol and midazolam for electroconvulsive therapy. I Anaesthesiol Clinic Pharmacol 2008;24:291-4.

77 Best N, Traugott F. Comparative evaluation of propofol or methohexitone as the sole anaesthetic agent for microlaryngeal surgery. Anaesth Intensive Care 1991;19:50-6.

78 Brownlie GS, Baker JA, Ogg TW. Propofol: bolus or continuous infusion. A day case technique for the vaginal termination of pregnancy. Anaesthesia 1991;46:775-7.

79 Canessa R, Lema G, Urzua J, Dagnino J, Concha M. Anesthesia for elective cardioversion: a comparison of four anesthetic agents. J Cardiothorac Vasc Anesth 1991;5:566-8.

80 Boysen K, Sanchez R, Krintel JJ, Hansen M, Haar PM, Dyrberg V. Induction and recovery characteristics of propofol, thiopental and etomidate. Acta Anaesthesiol Scand 1989;33:689-92.

81 Charuluxananan S, Kyokong O, Somboonviboon W, Lertmaharit S, Ngamprasertwong P, Nimcharoendee K. Nalbuphine versus propofol for treatment of intrathecal morphine-induced pruritus after cesarean delivery. Anesth Analg 2001;93:162-5.

82 Tan HL, Lee CY. Comparison between the effects of propofol and etomidate on motor and electroencephalogram seizure duration during electroconvulsive therapy. Anaesth Intensive Care 2009;37:807-14.

83 Eriksson M, Englesson S, Niklasson F, Hartvig P. Effect of lignocaine and $\mathrm{pH}$ on propofol-induced pain. Br J Anaesth 1997;78:502-6.

84 Gajraj NM, Nathanson MH. Pain during injection of propofol. Anaesthesia 1995;50:187.

85 Iyilikci L, Balkan BK, Gokel E, Gunerli A, Ellidokuz H. The effects of alfentanil or remifentanil pretreatment on propofol injection pain. J Clin Anesth 2004;16:499-502.

86 Jung JA, Choi BM, Cho SH, Choe SM, Ghim JL, Lee HM, et al. Effectiveness, safety, and pharmacokinetic and pharmacodynamic characteristics of microemulsion propofol in patients undergoing elective surgery under total intravenous anaesthesia. $\mathrm{Br}$ J Anaesth 2010;104:563-76.

87 Kinoshita M, Morioka N, Takada M, Ozaki M. The injection pain of propofol with different emulsion. Masui 2006;55:338-43.

88 Liljeroth E, Grauers A, Akeson J. Pain on injection of propofol with or without infusion of carrier fluid. Acta Anaesthesiol Scand 2001;45:839-41.

89 Mamiya H, Noma T, Fukuda K, Kasahara M, Ichinohe T, Kaneko Y Pain following intravenous administration of sedative agents: a comparison of propofol with three benzodiazepines. Anesth Prog 1998;45:18-21.

90 Parmar AK, Koay CK. Pain on injection of propofol. A comparison of cold propofol with propofol premixed with lignocaine. Anaesthesia 1998;53:79-83.

91 Ryu JH, Kim JH, Park KS, Do SH. Remifentanil-propofol versus fentanyl-propofol for monitored anesthesia care during hysteroscopy. J Clin Anesth 2008;20:328-32.

92 Sharpe P, Asif M, Victoria A, Rowbotham DJ. Iontophoretically applied lidocaine and the prevention of pain associated with the injection of intravenous propofol: a comparison with intravenous lidocaine. Eur J Anaesthesiol 2002;19:170-2.

93 Siddik-Sayyid SM, Aouad MT, Taha SK, Daaboul DG, Deeb PG, Massouh FM, et al. A comparison of sevoflurane-propofol versus sevoflurane or propofol for laryngeal mask airway insertion in adults. Anesth Analg 2005;100:1204-9.
94 Sun NC, Wong AY, Irwin MG. A comparison of pain on intravenous injection between two preparations of propofol. Anesth Analg 2005;101:675-8.

95 Yoshikawa T, Wajima Z, Inoue T, Ogura A, Ogawa R. Epidural anesthesia with lidocaine reduces propofol injection pain. Can J Anaesth 2001;48:538-44.

96 Eriksson M. Prilocaine reduces injection pain caused by propofol. Acta Anaesthesiol Scand 1995;39:210-3.

97 Batra YK, Al-Qattan AR, Ward VD, Kuriakose D, Ali SS, Alexander D. Remifentanil pretreatment for propofol injection pain in children. Can J Anaesth 2004;51:519-20.

98 Brock MF, Grace BE, Morley B, Hillegass G, Houle T, Groban L. Does lidocaine more effectively prevent pain upon induction with propofol or etomidate when given preemptively than when mixed with the drug? J Clin Anesth 2010;22:505-9.

99 Aldrete JA, Otero P, Alcover J, Parietti A, Johnson SC, Montpetit FH, et al. Pain on injection from propofol may be avoided by changing its formulation. Acta Anaesthesiol Scand 2010;54:442-6.

100 Aantaa R, Manner T, Kanto J. Induction characteristics of two brands of propofol in children. Curr Ther Res 1997;58:38-43.

101 Al-Refai AR, Al-Mujadi H, Ivanova MP, Marzouk HM, Batra YK, Al-Qattan AR. Prevention of pain on injection of propofol: a comparison of remifentanil with alfentanil in children. Minerva Anestesiol 2007;73:219-23.

102 Apiliogullari S, Keles B, Apiliogullari B, Balasar M, Yilmaz H, Duman A. Comparison of diphenhydramine and lidocaine for prevention of pain after injection of propofol: a double-blind, placebo-controlled, randomized study. Eur J Anaesthesiol 2007;24:235-8.

103 Beh T, Splinter W, Kim J. In children, nitrous oxide decreases pain on injection of propofol mixed with lidocaine. Can J Anaesth 2002;49:1061-3.

104 Bilotta F, Ferri F, Soriano SG, Favaro R, Annino L, Rosa G. Lidocaine pretreatment for the prevention of propofol-induced transient moto disturbances in children during anesthesia induction: a randomized controlled trial in children undergoing invasive hematologic procedures. Paediatr Anaesth 2006;16:1232-7.

105 Fahringer DL, Goodwin SR, Warde MK, Ye G, Blackwelder B, Ajala AM, et al. The effect of a 3:1 volume mixture of propofol $1 \%$ and thiopental $2.5 \%$ in reducing the pain on injection of propofol in children. Pediatr Anesth 2010;20:545-52.

106 Gutmann A, Pessenbacher K, Gschanes A, Eggenreich U, Wargenau M, Toller W. Propofol anesthesia in spontaneously breathing children undergoing magnetic resonance imaging: comparison of two propofol emulsions. Paediatr Anaesth 2006;16:266-74.

107 Hiller A, Saarnivaara L. Injection pain, cardiovascular changes and recovery following induction of anaesthesia with propofol in combination with alfentanil or lignocaine in children. Acta Anaesthesiol Scand 1992;36:564-8.

108 Kaabachi O, Chettaoui O, Ouezini R, Abdelaziz AB, Cherif R, Kokki H. A ketamine-propofol admixture does not reduce the pain on injection compared with a lidocaine-propofol admixture. Paediatr Anaesth 2007;17:734-7.

109 Kwak HJ. Prevention of propofol-induced pain in children: combination of alfebtanil and lidocaine vs alfenatnil or lidocaine alone. Br J Anaesth 2009;103:410-2.

110 Nyman Y, Von Hofsten K, Georgiadi A, Eksborg S, Lonnqvist PA Propofol injection pain in children: a prospective randomized double-blind trial of a new propofol formulation versus propofol with added lidocaine. BrJ Anaesth 2005;95:222-5.

111 Pellegrini M, Lysakowski C, Dumont L, Borgeat A, Tassonyi E. Propofol $1 \%$ versus propofol $2 \%$ in children undergoing minor ENT surgery. Br J Anaesth 2003;90:375-7.

112 Pickford A, Burden J, Lewis I. Propofol and pain on induction: the effect of injectate temperature in children. Paediatr Anaesth 2000;10:129-32.

113 Piotrowski R, Petrow N. Propofol versus thiopentone for induction of anesthesia in children after premedication with midazolam. Anaesthesist 1990;39:398-405.

114 Pollard RC, Makky S, McFadzean J, Ainsworth L, Goobie SM, Montgomery C). An admixture of $3 \mathrm{mg} \times \mathrm{kg}(-1)$ of propofol and $3 \mathrm{mg} \times \mathrm{kg}(-1)$ of thiopentone reduces pain on injection in pediatric anesthesia. Can J Anaesth 2002;49:1064-9.

115 Rochette A, Hocquet AF, Dadure C, Boufroukh D, Raux O, Lubrano JF, et al. Avoiding propofol injection pain in children: a prospective, randomized, double-blinded, placebo-controlled study. Br J Anaesth 2008;101:390-4.

116 Soltesz S, Silomon M, Graf G, Mencke T, Boulaadass S, Molter GP. Effect of a $0.5 \%$ dilution of propofol on pain on injection during induction of anesthesia in children. Anesthesiology 2007;106:80-4.

117 Varghese E, Krishna H, Nittala A. Does the newer preparation of propofol, an emulsion of medium/long chain triglycerides cause less injection pain in children when premixed with lignocaine? Pediatr Anesth 2010;20:338-42. 
118 Kobayashi Y, Tsuchida A, Kamada Y, Seki S, Ichimiya T, Namiki A. Effects of speed of injection on anesthesia induction with propofol and fentanyl. Masui 1999;48:847-51.

119 Scott RP, Saunders DA, Norman J. Propofol: clinical strategies for preventing the pain of injection. Anaesthesia 1988;43:492-4.

120 Stokes DN, Robson N, Hutton P. Effect of diluting propofol on the incidence of pain on injection and venous sequelae. Br J Anaesth 1989;62:202-3.

121 Angst MS, Mackey SC, Zupfer GH, Tataru CD, Brock-Utne JG. Reduction of propofol injection pain with a double lumen IV set. J Clin Anesth 1997;9:462-6.

122 Seki S, Sekine R, Aketa K, Kobayashi Y, Ichimiya T, Tsuchida H, et al. Induction of anesthesia with propofol injected through a central venous catheter. Masui 1999;48:62-6.

123 Briggs LP, White $M$. The effects of premedication on anaesthesia with propofol ("Diprivan"). Postgrad Med J 1985;61(suppl 3):35-7.

124 Briggs LP, Bahar M, Beers HT, Clarke RS, Dundee JW, Wright PJ, et al. Effect of preanaesthetic medication on anaesthesia with $\mathrm{ICl} 35,868$. BrJ Anaesth 1982;54:303-6.

125 McCulloch MJ, Lees NW. Assessment and modification of pain on induction with propofol (Diprivan). Anaesthesia 1985;40:1117-20.

126 Tariq MA, Kamran M. Incidence of pain on propofol injection and efficacy of addition of lignocaine or selecting big vein or both combined in reducing it: a randomized control trial. J Postgrad Med Inst 2006;20:8-11.

127 Davies AF, Vadodaria B, Hopwood B, Dexter T, Conn D. Efficacy of microfiltration in decreasing propofol-induced pain. Anaesthesia 2002; $57: 557-61$.

128 Hellier C, Newell S, Barry J, Brimacombe J. A 5-microm filter does not reduce propofol-induced pain. Anaesthesia 2003;58:802-3.

129 Barker P, Langton JA, Murphy P, Rowbotham DJ. Effect of prior administration of cold saline on pain during propofol injection. A comparison with cold propofol and propofol with lignocaine. Anaesthesia 1991;46:1069-70.

130 Divatia JV, Patil VP, Halikar V, NagbhidkarY, Kulkarni AP, Dasgupta D. Efficacy of lignocaine pretreatment and cold propofol in reducing pain during injection of propofol. J Anaesthesiol Clin Pharmacol 1999;15:279-83.

131 Fletcher GC, Gillespie JA, Davidson JA. The effect of temperature upon pain during injection of propofol. Anaesthesia 1996;51:498-9.

132 Kaya K, Ozkocak I, Akcabay M, Babacan A, Izdes S, Ocal E, et al. Effect of lidocaine addition to cold propofol and the propofol at room temperature on the propofol injection pain. Br J Anaesth 1995;74(suppl 1):140

133 Lin SS, Chen GT, Lin JC, Chen TY, Hwang MH. Pain on injection of propofol. Acta Anaesthesiol Sin 1994;32:73-6.

134 McCrirrick A, Hunter S. Pain on injection of propofol: the effect of injectate temperature. Anaesthesia 1990;45:443-4.

135 Nakane M, Iwama H. A potential mechanism of propofol-induced pain on injection based on studies using nafamostat mesilate. $\mathrm{Br}$ J Anaesth 1999;83:397-404.

136 Ozturk E, Izdes S, Babacan A, Kaya K. Temperature of propofol does not reduce the incidence of injection pain. Anesthesiology 1998;89:1041.

137 Uda R, Kadono N, Otsuka M, Shimizu S, Mori H. Strict temperature control has no effect on injection pain with propofol. Anesthesiology 1999;91:591-2.

138 Minogue SC, Sun DA. Bacteriostatic saline containing benzyl alcohol decreases the pain associated with the injection of propofol. Anesth Analg 2005;100:683-6.

139 Lees NW, McCulloch M, Mair WB. Propofol ("Diprivan") for induction and maintenance of anaesthesia. Postgrad Med ) 1985;61(suppl 3):88-9.

140 Gajraj NM, Nathanson MH. Preventing pain during injection of propofol: the optimal dose of lidocaine. J Clin Anesth 1996;8:575-7.

141 Gehan G, Karoubi P, Quinet F, Leroy A, Rathat C, Pourriat JL. Optimal dose of lignocaine for preventing pain on injection of propofol. $\mathrm{Br}$ J Anaesth 1991;66:324-6.

142 Goldmann R, Bornscheuer A, Kirchner E. [Effect of lidocaine administration mode on decreasing injection pain caused by propofol.] Anasthesiol Intensivmed Notfallmed Schmerzther 1997;32:98-100.

143 Helbo-Hansen S, Westergaard V, Krogh BL, Svendsen HP. The reduction of pain on injection of propofol: the effect of addition of lignocaine. Acta Anaesthesiol Scand 1988;32:502-4.

144 Ho CM, Tsou MY, Sun MS, Chu CC, Lee TY. The optimal effective concentration of lidocaine to reduce pain on injection of propofol. J Clin Anesth 1999;11:296-300.

145 Inoue S, Mitsuhata H, Shimizu R, Akazawa S, Kasuda H, Kawakami T, et al. Premixing lidocaine reduces the incidence and severity of pain on injection of propofol. Masui 1997;46:543-6.

146 Johnson RA, Harper NJ, Chadwick S, Vohra A. Pain on injection of propofol. Methods of alleviation. Anaesthesia 1990;45:439-42.
147 Karasawa F, Ehata T, Okuda T, Satoh T. Propofol injection pain is not alleviated by pretreatment with flurbiprofen axetil, a prodrug of a nonsteroidal antiinflammatory drug. J Anesth 2000;14:135-7.

148 King SY, Davis FM, Wells JE, Murchison DJ, Pryor PJ. Lidocaine for the prevention of pain due to injection of propofol. Anesth Analg 1992;74:246-9.

149 Krobbuaban B, Diregpoke S, Kumkeaw S, Tanomsat M. Comparison on pain on injection of a small particle-size lipid emulsion of propofol and standard propofol with or without lidocaine. J Med Assoc Thai 2005;88:1401-5.

150 Madenoglu H, Yildiz K, Dogru K, Boyaci A. Efficacy of different doses of lidocaine in the prevention of pain due to propofol injection: a randomized, open-label trial in 120 patients. Curr Ther Res 2003;64:310-6.

151 Mallick A, Elliot SC, Krishnan K, Vucevic M. Lidocaine is more efficient than the choice of propofol formulations to reduce incidence of pain on induction. Eur J Anaesthesiol 2007;24:403-7.

152 Massad IM, bu-Ali HM, bu-Halaweh SA, Badran IZ. Venous occlusion with lidocaine for preventing propofol induced pain. A prospective double-blind randomized study. Saudi Med J 2006;27:997-1000.

153 McCluskey A, Currer BA, Sayeed I. The efficacy of 5\% lidocaineprilocaine (EMLA) cream on pain during intravenous injection of propofol. Anesth Analg 2003;97:713-4.

154 Nakayama S, Furukawa H, Yanai H. Propofol reduces the incidence of emergence agitation in preschool-aged children as well as in schoolaged children: a comparison with sevoflurane. J Anesth 2007;21:19-23.

155 Nathanson MH, Gajraj NM. Pain on injection of propofol. Anaesthesia 1998;53:608.

156 Nonaka A, Tamaki F, Sugawara T, Oguchi T, Kashimoto S, Kumazawa T. Premixing of $5 \%$ dextrose in Ringer's acetate solution with propofol reduces incidence and severity of pain on propofol injection. Masui 1999;48:862-7.

157 Nonaka A, Tamaki F, Suzuki M, Suzuki S, Kumazawa T. Effect of pre mixed lidocaine with propofol on propofol injection pain in elderly patients. Masui 2000;49:1235-8.

158 Tham CS, Khoo ST. Modulating effects of lignocaine on propofol. Anaesth Intensive Care 1995;23:154-7.

159 Tsubokura H, Inagaki Y, Adachi H, Otsuki A, Harada T, Hirosawa J, et al. Efficacy of simultaneous bolus injection of lidocaine with propofol on pain caused by propofol injection. Masui 2001;50:1196-200.

160 Yokota S, Komatsu T, Komura Y, Nishiwaki K, Kimura T, Hosoda R, et al. Pretreatment with topical $60 \%$ lidocaine tape reduces pain on injection of propofol. Anesth Analg 1997;85:672-4.

161 Mok MS, Pang WW, Hwang MH. The analgesic effect of tramadol, metoclopramide, meperidine and lidocaine in ameliorating propofol injection pain: a comparative study. J Anaesth Clin Pharmacol 1999;15:37-42.

162 Reddy MS, Chen FG, Ng HP. Effect of ondansetron pretreatment on pain after rocuronium and propofol injection: a randomised, doubleblind controlled comparison with lidocaine. Anaesthesia 2001;56:902-5.

163 Wong WH, Cheong KF. Role of tramadol in reducing pain on propofol injection. Singapore Med / 2001;42:193-5.

164 Zashedi H, Nikooseresht M, Seifrabie M. Prevention of propofol injection pain with small-dose ketamine. Middle East J Anesthesiol 2009;20:401.

165 Adachi H, Inagaki Y, Harada T, Tsubokura H, Otsuki A, Hirosawa J, et al. Effects of concentration and dosage of lidocaine on preventing the pain on injection of propofol. Masui 2002;51:983-7.

166 Azma T, Kawai K, Tamura H, Okada K, Okida M. Comparative benefit of preemptively applied thiopental for propofol injection pain: the advantage over lidocaine. Hiroshima J Med Sci 2004;53:13-6.

167 Ganta R, Fee JP. Pain on injection of propofol: comparison of lignocaine with metoclopramide. Br / Anaesth 1992;69:316-7.

168 Honarmand A, Safavi M. Magnesium sulphate pretreatment to alleviate pain on propofol injection: a comparison with ketamine or lidocaine. Acute Pain 2008;10:23-9.

169 Kajiyama S, Osawa Y, Okada Y. Effects of the injection method of lidocaine on preventing injection pain during anesthesia induction by target controlled infusion with propofol. Masui 2009;58:891.

170 Kaya S, Turhanoglu S, Karaman H, Ozgun S, Basak N. Lidocaine for prevention of propofol injection-induced pain: a prospective, randomized, double-blind, controlled study of the effect of duration of venous occlusion with a tourniquet in adults. Curr Ther Res 2008;69:29-35.

171 Lee P, Russell W]. Preventing pain on injection of propofol: a comparison between lignocaine pre-treatment and lignocaine added to propofol. Anaesth Intensive Care 2004;32:482-4.

172 Lee TW, Loewenthal AE, Strachan JA, Todd BD. Pain during injection of propofol. The effect of prior administration of thiopentone. Anaesthesia 1994;49:817-8. 
173 Lyons B, Lohan D, Flynn C, McCarroll M. Modification of pain on injection of propofol. A comparison of pethidine and lignocaine. Anaesthesia 1996;51:394-5.

174 McDonald DS, Jameson P. Injection pain with propofol. Reduction with aspiration of blood. Anaesthesia 1996;51:878-80.

175 Newcombe GN. The effect, on injection pain, of adding lignocaine to propofol. Anaesth Intensive Care 1990;18:105-7.

176 Nicol ME, Moriarty J, Edwards J, Robbie DS, A'Hern RP. Modification of pain on injection of propofol-a comparison between lignocaine and procaine. Anaesthesia 1991;46:67-9.

177 Oka S, Ogura A, Terada M, Gemba A, Abe A, Yabe Y, et al. Clinical methods for diminishing pain associated with injection of the initial dose of propofol used for intravenous sedation by target controlled infusion. J Jpn Dental Soc Anesthesiol 2008;36:21-7.

178 Smith I, Ding Y, White PF. Muscle pain after outpatient laparoscopyinfluence of propofol versus thiopental and enflurane. Anesth Analg 1993;76:1181-4.

179 Fletcher JE, Seavell CR, Bowen DJ. Pretreatment with alfentanil reduces pain caused by propofol. Br J Anaesth 1994;72:342-4.

180 Helmers JH, Kraaijenhagen RJ, Leeuwen L, Zuurmond WW. Reduction of pain on injection caused by propofol. Can J Anaesth 1990;37:267-8

181 Nathanson MH, Gajraj NM, Russell JA. Prevention of pain on injection of propofol: a comparison of lidocaine with alfentanil. Anesth Analg 1996;82:469-71.

182 Saarnivaara L, Klemola UM. Injection pain, intubating conditions and cardiovascular changes following induction of anaesthesia with propofol alone or in combination with alfentanil. Acta Anaesthesiol Scand 1991;35:19-23.

183 Wall RJ, Zacharias M. Effects of alfentanil on induction and recovery from propofol anaesthesia in day surgery. Anaesth Intensive Care 1990;18:214-8

184 Wrench IJ, Girling KJ, Hobbs GJ. Alfentanil-mediated analgesia during propofol injection: no evidence for a peripheral action. Br J Anaesth 1996;77:162-4.

185 Basaranoglu G, Erden V, Delatioglu H. Reduction of pain on injection of propofol: a comparison of fentanyl with remifentanil. Anesth Analg 2002;94:1040-1.

186 Basaranoglu G, Erden V, Delatioglu H, Saitoglu L. Reduction of pain on injection of propofol using meperidine and remifentanil. Eur J Anaesthesiol 2005;22:890-2.

187 Honarmand A, Safavi M. Prevention of propofol-induced injection pain by sufentanil: a placebo-controlled comparison with remifentanil. Clin Drug Investig 2008;28:27-35.

188 Lee JR, Jung CW, Lee YH. Reduction of pain during induction with target-controlled propofol and remifentanil. Br J Anaesth 2007;99:876-80.

189 Roehm KD, Piper SN, Maleck WH, Boldt J. Prevention of propofolinduced injection pain by remifentanil: a placebo-controlled comparison with lidocaine. Anaesthesia 2003;58:165-70.

190 Collins LM, Cooney CM, Fitzpatrick G. Propofol induction characteristics after fentanyl or midazolam and fentanyl. Br J Anaesth 1997;79:676-7P.

191 Agarwal A, Raza M, Dhiraaj S, Pandey R, Gupta D, Pandey CK, et al. Pain during injection of propofol: the effect of prior administration of butorphanol. Anesth Analg 2004;99:117-9.

192 Iwata M, Inoue S, Kawaguchi M, Kimura T, Tojo T, Taniguchi S, et al. Ketamine eliminates propofol pain but does not affect hemodynamics during induction with double-lumen tubes. J Anesth 2010;24:31-7.

193 Koo SW, Cho SJ, Kim YK, Ham KD, Hwang JH. Small-dose ketamine reduces the pain of propofol injection. Anesth Analg 2006;103:1444-7.

194 Suzuki S, Masamune T, Nonaka A, Kumazawa T. Pre-treatment with ketamine reduces incidence and severity of pain on propofol injection. Masui 2002;51:140-3.

195 Tarmiz K. Efficacy of low dose of ketamine in reduction of propofol injection-related pain. Ann Fr Anesth Reanim 2010;28:171-80.

196 Tan CH, Onsiong MK, Kua SW. The effect of ketamine pretreatment on propofol injection pain in 100 women. Anaesthesia 1998;53:302-5.

197 Nishiyama T. How to decrease pain at rapid injection of propofol: effectiveness of flurbiprofen. J Anesth 2005;19:273-6.

198 Mohta M, Agarwal D, Sethi AK, Sandhu K. Effect of diclofenac pretreatment on pain during propofol injection. Anaesth Intensive Care 2004;32:765-9.

199 Huang YW, Buerkle H, Lee TH, Lu CY, Lin CR, Lin SH, et al. Effect of pretreatment with ketorolac on propofol injection pain. Acta Anaesthesiol Scand 2002;46:1021-4.

200 Smith AJ, Power I. The effect of pretreatment with ketorolac on pain during intravenous injection of propofol. Anaesthesia 1996;51:883-5.

201 Yull DN, Barkshire KF, Dexter T. Pretreatment with ketorolac and venous occlusion to reduce pain on injection of propofol. Anaesthesia 2000;55:284-7.
202 Allford MA, Mensah JA. Discomfort on injection: a comparison between two formulations of propofol. Eur J Anaesthesiol 2006;23:971-4.

203 Bachmann-Mennenga B, Ohlmer A, Boedeker RH, Mann M, Muhlenbruch B, Heesen M. Preventing pain during injection of propofol: effects of a new emulsion with lidocaine addition. Eur Anaesthesiol 2007;24:33-8.

204 Doenicke AW, Roizen MF, Rau J, O’Connor M, Kugler J, Klotz U, et al. Pharmacokinetics and pharmacodynamics of propofol in a new solvent. Anesth Analg 1997;85:1399-403.

205 Knibbe CA, Voortman HJ, Aarts LP, Kuks PF, Lange R, Langemeijer HJ, et al. Pharmacokinetics, induction of anaesthesia and safety characteristics of propofol $6 \%$ SAZN vs propofol $1 \%$ SAZN and diprivan-10 after bolus injection. Br J Clin Pharmacol 1999;47:653-60.

206 Kunitz O, Losing R, Schulz-Stubner S, Haaf-Von-Below S, Rossaint R, Kuhlen R. Propofol-LCT versus propofol-MCT/LCT with or without lidocaine-a comparison on pain on injection. Anasthesiol Intensivmed Notfallmed Schmerzther 2004;39:10-4

207 Larsen B, Beerhalter U, Biedler A, Brandt A, Doege F, Brun K, et al. Less pain on injection by a new formulation of propofol? A comparison with propofol LCT. Anaesthesist 2001:50:842-5.

208 Lassnigg A, Janoschek U, Gschanes A, Liedler A, Hutschala D, Eggenreich U, et al. Propofol $2 \%$ in two different oil-in-water emulsions: a randomized, double-blind study. Can J Anaesth 2003;50:964-5.

209 Liljeroth E, Akeson J. Less local pain on intravenous infusion of a new propofol emulsion. Acta Anaesthesiol Scand 2005;49:248-51.

210 Nagao N, Uchida T, Nakazawa K, Makita K. Medium-/long-chain triglyceride emulsion reduced severity of pain during propofol injection. Can J Anesth 2005;52:660-1.

211 Ohmizo H, Obara S, Iwama H. Mechanism of injection pain with lon and long-medium chain triglyceride emulsive propofol. Can J Anaesth 2005;52:595-9.

212 Paul M, Dueck M, Kampe S, Fruendt H, Kasper SM. Pharmacological characteristics and side effects of a new galenic formulation of propofol without soyabean oil. Anaesthesia 2003;58:1056-62.

213 Rau J, Roizen MF, Doenicke AW, O’Connor MF, Strohschneider U. Propofol in an emulsion of long- and medium-chain triglycerides: the effect on pain. Anesth Analg 2001;93:382-4.

214 Song D, Hamza MA, White PF, Byerly SI, Jones SB, Macaluso AD. Comparison of a lower-lipid propofol emulsion with the standard emulsion for sedation during monitored anesthesia care. Anesthesiology 2004;100:1072-5.

215 Song D, Hamza M, White PF, Klein K, Recart A, Khodaparast O. The pharmacodynamic effects of a lower-lipid emulsion of propofol: a comparison with the standard propofol emulsion. Anesth Analg 2004; $98: 687-91$.

216 Sundarathiti $P$, Boonthom N, Chalacheewa T, Jommaroeng $P$, Rungsithiwan W. A comparison of propofol-LCT with propofol-LCT/ MCT on pain of injection. J Med Assoc Thai 2007;90:2683-8.

217 Suzuki H, Miyazaki H, Andoh T, Yamada Y. Propofol formulated with long-/medium-chain triglycerides reduces the pain of injection by target controlled infusion. Acta Anaesthesiol Scand 2006;50:568-71.

218 Ueki R, Tanimoto M, Tatara T, Tsujimoto S, Kaminoh Y, Tashiro C. Emulsion of flurbiprofen axetil reduces propofol injection pain due to a decrease in free propofol concentration. J Anesth 2007;21:325-9.

219 Yamakage M, Iwasaki S, Jeong SW, Ishiyama SI, Namiki A. Comparative study between propofol in a long-chain triglyceride and propofol in a medium/long-chain triglyceride during sedation with target-controlled infusion. Anaesth Intensive Care 2005;33:351-5.

220 Adam S, van Bommel J, Pelka M, Dirckx M, Jonsson D, Klein J. Propofol-induced injection pain: comparison of a modified propofol emulsion to standard propofol with premixed lidocaine. Anesth Analg 2004;99:1076-9.

221 Ahmad N, Zanariah Y, Balan S. Fentanyl pre-treatment alleviates pain during injection of propofol-lipuro premixed with lignocaine. Med ) Malaysia 2008;63:431.

222 Burimsittichai R, Kumwilaisuk K, Charuluxananan S, Tingthanathikul W, Premsamran P, Sathapanawath N. Pain on injection of propofol: propofol LCT vs propofol MCT/LCT with or without lidocaine pretreatment. J Med Assoc Thai 2006;89(suppl 3):S86-91.

223 Kam E, Abdul-Latif MS, McCluskey A. Comparison of Propofol-Lipuro with propofol mixed with lidocaine $10 \mathrm{mg}$ on propofol injection pain. Anaesthesia 2004:59:1167-9.

224 Rohm KD, Piper SN, Schollhorn TA, Suttner SW, Maleck WH, Boldt J. Injection pain secondary to propofol-MCT/LCT and propofol-LCTcomparison of prophylaxis with lidocaine. Anasthesiol Intensivmed Notfallmed Schmerzther 2003;38:643-7.

225 Schaub E, Kern C, Landau R. Pain on injection: a double-blind comparison of propofol with lidocaine pretreatment versus propofol formulated with long- and medium-chain triglycerides. Anesth Analg 2004;99:1699-702. 
226 Sethi N, Jayaraman L, Sethi M, Sharma S, Sood J. Prevention of propofol pain: a comparative study. Middle East J Anesthesiol 2009;20:71-4

227 Yew WS, Chong SY, Tan KH, Goh MH. The effects of intravenous lidocaine on pain during injection of medium- and long-chain triglyceride propofol emulsions. Anesth Analg 2005;100:1693-5.

228 Agarwal A, Ansari MF, Gupta D, Pandey R, Raza M, Singh PK, et al. Pretreatment with thiopental for prevention of pain associated with propofol injection. Anesth Analg 2004;98:683-6.

229 Alyafi WA, Rangasami J. Reduction of propofol pain-fentanyl vs lidocaine. Middle East J Anesthesiol 1996;13:613-9.

230 Asik I, Yorukoglu D, Gulay I, Tulunay M. Pain on injection of propofol: comparison of metoprolol with lidocaine. Eur J Anaesthesiol 2003;20:487-9.

231 Batra YK, Al Qattan AR, Marzouk HM, Smilka M, Agzamov A. Ketamine pretreatment with venous occlusion attenuates pain on injection with propofol. Eur J Anaesthesiol 2005;22:69-70.

232 Canbay O, Celebi N, Arun O, Karagoz AH, Saricaoglu F, Ozgen S. Efficacy of intravenous acetaminophen and lidocaine on propofo injection pain. Br J Anaesth 2008;100:95-8.

233 Dubey PK, Prasad SS. Pain on injection of propofol: the effect of granisetron pretreatment. Clin J Pain 2003;19:121-4.

234 Kwak KH, Ha J, Kim Y, Jeon Y. Efficacy of combination intravenous lidocaine and dexamethasone on propofol injection pain: a randomized, double-blind, prospective study in adult Korean surgical patients. Clin Ther 2008;30:1113-9.

235 Liaw WJ, Pang WW, Chang DP, Hwang MH. Pain on injection of propofol: the mitigating influence of metoclopramide using differen techniques. Acta Anaesthesiol Scand 1999;43:24-7.

236 Piper SN, Rohm KD, Papsdorf M, Maleck WH, Mattinger P, Boldt J. Dolasetron reduces pain on injection of propofol. Anasthesiol Intensivmed Notfallmed Schmerzther 2002;37:528-31.

237 Sadler PJ, Thompson HM, Maslowski P, Liddle A, Rowbotham DJ. Iontophoretically applied lidocaine reduces pain on propofol injection. Br J Anaesth 1999;82:432-4.

238 Mattila MAK, Koski EMJ. Venous sequelae after intravenous propofo ("Diprivan"- a comparison with methohexitone in short anaesthesia. Postgrad Med J 1985;61(suppl 3):162-4.

239 Stark RD, Binks SM, Dutka VN, O’Connor KM, Arnstein MJ, Glen JB. A review of the safety and tolerance of propofol ("Diprivan"). Postgrad Med ) 1985;61(suppl 3):152-6.

240 Sterne JA, Egger M, Smith GD. Systematic reviews in health care: investigating and dealing with publication and other biases in metaanalysis. BMJ 2001;323:101-5.

241 Marret E, Kurdi O, Zufferey P, Bonnet F. Effects of nonsteroidal antiinflammatory drugs on patient-controlled analgesia morphine side effects: meta-analysis of randomized controlled trials. Anesthesiology 2005;102:1249-60.

242 Kakinohana M, Higa Y, Sasara T, Saikawa S, Miyata Y, Tomiyama H, et al. Addition of ketamine to propofol-fentanyl anaesthesia can reduce post-operative pain and epidural analgesic consumption in upper abdominal surgery. Acute Pain 2004;5:75-9.

243 Leeson RM, Harrison S, Ernst CC, Hamilton DA, Mermelstein FH, Gawarecki DG, et al. Dyloject, a novel injectable diclofenac formulation, offers greater safety and efficacy than voltarol for postoperative dental pain. Reg Anesth Pain Med 2007;32:303-10.

244 McAlister FA, Straus SE, Sackett DL, Altman DG. Analysis and reporting of factorial trials: a systematic review. JAMA 2003;289:2545-53.

245 Eti Z, Gogus FY. A reliable method for preventing pain on injection of propofol. J Anesth 1999;13:175-7.

246 Huang CL, Wang YP, Cheng YJ, Susetio L, Liu CC. The effect of carrie intravenous fluid speed on the injection pain of propofol. Anesth Analg 1995;81:1087-8

247 Grauers A, Liljeroth E, Akeson J. Propofol infusion rate does not affect local pain on injection. Acta Anaesthesiol Scand 2002;46:361-3.

248 Kobayashi Y, Tsuchida A, Kamada Y, Seki S, Ichimiya T, Namiki A Effects of the bolus injection rate on anesthesia induction with propofol. Masui 1999;48:852-5.

249 Erdil FA, Gulhas N, But AK, Begec Z, Ersoy MO. Does single dose premedication of dexmedetomidine reduce pain during injection of propofol? Pain Clinic 2007;19:21-5.

250 Yoshikawa T, Wajima Z, Ogura A, Inoue T, Ogawa R. Orally administered clonidine significantly reduces pain during injection of propofol. Br J Anaesth 2001;86:874-6.

251 Ambesh SP, Dubey PK, Sinha PK. Ondansetron pretreatment to alleviate pain on propofol injection: a randomized, controlled, double-blinded study. Anesth Analg 1999;89:197-9.

252 Haugen RD, Vaghadia H, Waters T, Merrick PM. Thiopentone pretreatment for propofol injection pain in ambulatory patients. Can Anaesth 1995;42:1108-12.

253 Kau YC, Wu RS, Cheng KS. Propofol-sodium thiopental admixture reduces pain on injection. Acta Anaesthesiol Sin 2000;38:9-13.
254 Thompson N, Robertson GS. Comparison of propofol and a propofolmethohexitone mixture for induction of day-case anaesthesia. $\mathrm{Br} J$ Anaesth 1996;77:213-6.

255 Fragen RJ, De Grood PM, Robertson EN, Booij LH, Crul JF. Effects of premedication on diprivan induction. Br J Anaesth 1982;54:913-6.

256 Shah MH, Gandhi S, Chadha IA. Comparison of midazolam coinduction with propofol predosing for induction of anaesthesia.J Anaesthesiol Clin Pharmacol 2008;24:197-200.

257 Galvez-Escalera I, Thorpe CM. The effect of coinduction with midazolam on propofol injection pain. Eur J Anaesthesiol 2004;21:579-81.

258 Hampl KF, Marsch SCU, Erb T, Drewe J, Schneider MC. Intravenous sedation for retrobulbar injection and eye surgery. Diazepam and/or propofol? Acta Anaesthesiol Scand 1996;40:53-8.

259 Pang WW, Mok MS, Wang CS, Yeh M, Chang DP. Can neostigmine reduce propofol injection pain? Acta Anaesthesiol Sin 2002;40:65-9.

260 Iwama H, Nakane M, Ohmori S, Kaneko T, Kato M, Watanabe K, et al. Nafamostat mesilate, a kallikrein inhibitor, prevents pain on injection with propofol. Br J Anaesth 1998;81:963-4.

261 Nakayama M, Ichinose H, Yamamoto S, Satoh O, Nakabayashi K, Hayashi $M$, et al. The effect of lidocaine on the bispectral index during anesthesia induction with propofol. Masui 2001;50:1213-6.

262 Aouad MT, Siddik-Sayyid SM, Al-Alami AA, Baraka AS. Multimodal analgesia to prevent propofol-induced pain: pretreatment with remifentanil and lidocaine versus remifentanil or lidocaine alone. Anesth Analg 2007;104:1540-4.

263 Jones D, Prankerd R, Lang C, Chilvers M, Bignell S, Short T. Propofolthiopentone admixture-hypnotic dose, pain on injection and effect on blood pressure. Anaesth Intensive Care 1999;27:346-56.

264 Barbi E, Marchetti F, Gerarduzzi T, Neri E, Gagliardo A, Sarti A, et al. Pretreatment with intravenous ketamine reduces propofol injection pain. Paediatr Anaesth 2003;13:764-8.

265 Mecklem DW. Propofol injection pain: comparing the addition of lignocaine or metoclopramide. Anaesth Intensive Care 1994;22:568-70.

266 Iwama H. A randomized, double-blind trial comparing the effect of mixing propofol with either lidocaine or nafamostat mesilate on injection pain. J Anesth 2000;14:164-5.

267 Austin JD, Parke TJ. Admixture of ephedrine to offset side effects of propofol: a randomized, controlled trial. J Clin Anesth 2009;21:44-9.

268 Agarwal A, Dhiraj S, Raza M, Pandey R, Pandey CK, Singh PK, et al. Vein pretreatment with magnesium sulfate to prevent pain on injection of propofol is not justified. Can J Anaesth 2004;51:130-3.

269 Memis D, Turan A, Karamanlioglu B, Sut N, Pamukcu Z. The use of magnesium sulfate to prevent pain on injection of propofol. Anesth Analg 2002;95:606-8.

270 O'Hara JR Jr, Sprung J, Laseter JT, Maurer WG, Carpenter T, Beven M, et al. Effects of topical nitroglycerin and intravenous lidocaine on propofol-induced pain on injection. Anesth Analg 1997;84:865-9.

271 Turan A, Karamanlioglu B, Memis D, Pamukcu Z. Prevention of propofol injection pain in patients using transdermal nitroglycerine. Turk Anesteziyoloji ve Reanimasyon 2002;30:152-5.

272 Wilkinson D, Anderson M, Gauntlett IS. Pain on injection of propofol: modification by nitroglycerin. Anesth Analg 1993;77:1139-42.

273 Harmon D, Rozario C, Lowe D. Nitrous oxide/oxygen mixture and the prevention of pain during injection of propofol. Eur J Anaesthesiol 2003;20:158-61.

274 Niazi A, Galvin E, Elsaigh I, Wahid Z, Harmon D, Leonard I. A combination of lidocaine and nitrous oxide in oxygen is more effective in preventing pain on propofol injection than either treatment alone. Eur J Anaesthesiol 2005;22:299-302.

275 Sinha PK, Neema PK, Rathod RC. Effect of nitrous oxide in reducing pain of propofol injection in adult patients. Anaesthesia Intensive Care 2005;33:235-8.

276 Dewandre J, Van Bos R, Van Hemelrijck J, Van Aken H. A comparison of the $2 \%$ and $1 \%$ formulations of propofol during anaesthesia for craniotomy. Anaesthesia 1994;49:8-12.

277 Agarwal A, Dhiraaj S, Raza M, Singhal V, Gupta D, Ranjan R, et al. Pain during injection of propofol: the effect of prior administration of ephedrine. Anaesth Intensive Care 2004:32:657-60.

278 Cheong MA, Kim KS, Choi WJ. Ephedrine reduces the pain from propofol injection. Anesth Analg 2002;95:1293-6.

279 Singh M, Mohta M, Sethi AK, Tyagi A. Efficacy of dexamethasone pretreatment for alleviation of propofol injection pain. Eur J Anaesthesiol 2005;22:888-90.

280 Uda R, Ohtsuka M, Doi Y, Inamori K, Kunimasa K, Ohnaka M, et al. Sixty percent lidocaine tape alleviates pain on injection of propofol after diminishing venipuncture pain. Masui 1998;47:843-7.

281 Yoshimura Y, Iwasaki T, Shimizu Y, Takasaki M. Nicorandil reduces incidence and severity of pain on propofol injection. Masui 2003;52:1204-6.

282 Gill PS, Shah J, Ogilvy A. Midazolam reduces the dose of propofol required for induction of anaesthesia and laryngeal mask airway insertion. Eur J Anaesthesiol 2001;18:166-70. 
283 Dedic A, Adam S, Gommers D, Van Bommel J. Propofol injection pain -is it still an issue? The effect of premedication. Minerva Anestesio 2010;76:720-4.

284 Saadawy I, Ertok E, Boker A. Painless injection of propofol: pretreatment with ketamine vs thiopental, meperidine, and lidocaine. Middle East J Anesthesiol 2007;19:631-44.

285 Kaya FN, Yavascaoglu B, Basagan Mogol E, Iscimen R, Ozcan B. Esmolol reduces pain on injection of propofol. Pain Clinic 2006;18:361-6.

286 Uzun S, Karagoz E, Kose A, Canbay O, Ozgen S. Dexmedetomidine for prevention of propofol injection pain. J Anaesth Clin Pharmacol 2008;24:406-8.

287 Ozkocak I, Altunkaya H, Ozer Y, Ayoglu H, Demirel CB, Cicek E. Comparison of ephedrine and ketamine in prevention of injection pain and hypotension due to propofol induction. Eur J Anaesthesiol 2005;22:44-8
288 Ghai B, Makkar JK, Bala I, Wig J. Effect of parecoxib pretreatment and venous occlusion on propofol injection pain: a prospective, randomized, double-blinded, placebo-controlled study. J Clin Anesth 2010;22:88-92

289 Borazan H, Erdem TB, Kececioglu M, Otelcioglu S. Prevention of pain on injection of propofol: a comparison of lidocaine with different doses of paracetamol. Eur J Anaesthesiol 2010;27:253.

290 Kwak K, Kim J, Park S, Lim D, Kim S, Baek W, et al. Reduction of pain on injection of propofol: combination of pretreatment of remifentanil and premixture of lidocaine with propofol. Eur J Anaesthesiol 2007;24:746-50.

291 Hwang I, Noh II, Im Kim S, Kim MG, Park SY, Kim SH, et al. Prevention of pain with the injection of microemulsion propofol: a comparison of a combination of lidocaine and ketamine with lidocaine or ketamine alone. Korean J Anesthesiol 2010;59:233.

Accepted: 17 January 2011 